\title{
Detection of SARS-CoV-2 in air and on surfaces in rooms of infected nursing home residents
}

K.J. Linde ${ }^{1}$, I.M. Wouters ${ }^{1}$, J.A.J.W. Kluytmans ${ }^{5}$, M.F.Q. Kluytmans-van den Bergh ${ }^{5,6}$, S.D. Pas ${ }^{3}$, C.H. GeurtsvanKessel ${ }^{2}$, M.P.G. Koopmans, ${ }^{6}$ M. Meier ${ }^{4}$, P. Meijer ${ }^{1}$, C.R. Raben ${ }^{1}$, J. Spithoven ${ }^{1}$, M.H.G. TersteegZijderveld ${ }^{1}$, D.J.J. Heederik ${ }^{1}$, W. Dohmen ${ }^{1}$ and COCON consortium

${ }^{1}$ Institute for Risk Assessment Sciences, Utrecht University, Utrecht, the Netherlands

${ }^{2}$ Department of ViroScience, Erasmus MC, Rotterdam, the Netherlands

${ }^{3}$ Microvida location Amphia/Bravis, Breda/Roosendaal, the Netherlands

${ }^{4}$ Mijzo, Waalwijk, the Netherlands

5 Julius Center for Health Sciences and Primary Care, University Medical Center Utrecht, Utrecht University, Utrecht, the Netherlands

${ }^{6}$ Department of Infection Control, Amphia Hospital, Breda, the Netherlands

Corresponding author: K J Linde

e-mail: K.j.linde@uu.nl Institute for Risk Assessment Sciences Division Environmental Epidemiology PO Box 80178 3508TD Utrecht The Netherlands 
medRxiv preprint doi: https://doi.org/10.1101/2022.02.16.22271053; this version posted February 25, 2022. The copyright holder for this preprint

(which was not certified by peer review) is the author/funder, who has granted medRxiv a license to display the preprint in perpetuity.

All rights reserved. No reuse allowed without permission.

\section{Abstract}

There is an ongoing debate on airborne transmission of Severe Acute Respiratory Syndrome Coronavirus 2 (SARS-CoV-2) as a risk factor for infection. In this study, the level of SARS-CoV-2 in air and on surfaces of SARS-CoV-2 infected nursing home residents was assessed to gain insight in potential transmission routes.

During outbreaks, air samples were collected using three different active and one passive air sampling technique in rooms of infected patients. Oropharyngeal swabs (OPS) of the residents and dry surface swabs were collected. Additionally, longitudinal passive air samples were collected during a period of 4 months in common areas of the wards. Presence of SARS-CoV-2 RNA was determined using RT-qPCR, targeting the RdRp- and E-genes. OPS, samples of two active air samplers and surface swabs with $\mathrm{Ct}$ value $\leq 35$ were tested for the presence of infectious virus by cell culture. In total, 360 air and 319 surface samples from patient rooms and common areas were collected. In rooms of 10 residents with detected SARS-CoV-2 RNA in OPS, SARS-CoV-2 RNA was detected in 93 of 184 collected environmental samples (50.5\%) (lowest Ct 29,5$)$, substantially more than in the rooms of residents with negative OPS on the day of environmental sampling $(n=2)(3.6 \%)$. SARS-CoV-2 RNA was most frequently present in the larger particle size fractions (>4 $\mu \mathrm{m} 60 \%(6 / 10) ; 1-4 \mu \mathrm{m} 50 \%$ $(5 / 10) ;<1 \mu \mathrm{m} \mathrm{20 \%} \mathrm{(2/10))} \mathrm{(Fischer} \mathrm{exact} \mathrm{test} p=0.076)$. The highest proportion of RNA-positive air samples on room level was found with a filtration-based sampler $80 \%(8 / 10)$ and the cyclone-based sampler 70\% (7/10), and impingement-based sampler 50\% (5/10). SARS-CoV-2 RNA was detected in ten out of twelve (83\%) passive air samples in patient rooms. Both high-touch and low-touch surfaces contained SARS-CoV-2 genome in rooms of residents with positive OPS (high 38\% (21/55); low 50\% (22/44)). In one active air sample, infectious virus in vitro was detected.

In conclusion, SARS-CoV-2 is frequently detected in air and on surfaces in the immediate surroundings of room-isolated COVID-19 patients, providing evidence of environmental contamination. The environmental contamination of SARS-CoV-2 and infectious aerosols confirm the potential for transmission via air up to several meters.

Keywords: SARS-CoV-2, nursing home, air levels, surface 


\section{Introduction}

The ongoing pandemic, caused by Severe Acute Respiratory Syndrome Coronavirus 2 (SARS-CoV-2), continues to constitute a public health emergency of international concern. There is consensus on the role of direct contact transmission and airborne transmission at short distances (up to several meters) through large droplets. There is an ongoing debate on transmission through fomites and airborne transmission at larger distances (up to more than several meters) as a risk factor for subsequent infection ${ }^{1,2}$. The relative importance of this mode of transmission as driver of the pandemic is unknown. Several modes of transmission through the environment as a possible risk of infection of SARS-CoV-2 is considered important for groups at high risk ${ }^{3}$.

Previous studies investigating SARS-CoV-2 air concentrations in healthcare facilities showed contradictory results. In a limited number of studies in hospital settings, SARS-CoV-2 has been detected in air in proximity $(2-5 \mathrm{~m})$ of COVID-19 patients ${ }^{1,4-8}$. Other studies did not find evidence of SARS-CoV-2 in air ${ }^{9-12}$. However, the comparability of studies is limited due to differences in sampling methods, sampling duration and distance to infected persons. Oropharyngeal swabs were not consistently collected from infected persons for confirmation of infection and the actual level SARSCoV-2 shedding in addition to the collection of air samples. Infectiousness of SARS-CoV-2 detected in air was not investigated in most studies ${ }^{4-7}$ or could not be shown ${ }^{13,14}$. Infectivity and amount of shed virus have been reported to rapidly decline during the first week after illness onset ${ }^{15,16}$. As viral RNA can persist and be shed for prolonged periods of time without being infectious, it is important to investigate the viability of virus in air to understand airborne transmission routes of the virus. Therefore, to successfully investigate modes of transmission of SARS-CoV-2, it seems crucial to investigate SARS-CoV-2 air concentrations in the first days following infection.

After the first pandemic wave in the Netherlands, nursing homes had introduced enhanced surveillance screening for SARS-CoV-2, which led to identification of new infections at an early stage

17. To determine airborne transmission risks from SARS-CoV-2 infected patients to their immediate surroundings, we measured SARS-CoV-2 in air and on surfaces in Dutch nursing home residencies as well as in rooms of SARS-CoV-2 isolated infected nursing home residents.

\section{Methods and materials}

The study consisted of two arms: a series of environmental investigations during outbreaks and longitudinal air monitoring (Figure 1). Weekly SARS-CoV-2 infections were registered and notified in 28 nursing homes from Mijzo Care organisation in Noord-Brabant in the Netherlands. In case of two 
or more confirmed SARS-CoV-2 infections in residents within the same ward, an outbreak investigation was initiated, consisting of extensive environmental sample collection and SARS-CoV-2 testing of persons. In a subsample of 3 of the 28 nursing homes, longitudinal monitoring took place in the direct living environment. No medical ethical approval was needed for this study as evaluated by the Medical Research Ethics Committee of University Medical Centre Utrecht; a declaration of non-compliance with the scope of the Dutch Medical Research Involving Human Subject Act was obtained. The study was conducted in agreement with the European legislation on handling privacysensitive data.

\section{Outbreak investigation}

Residents of the nursing homes were tested for possible SARS-CoV-2 infection in case they experienced COVID-19 related symptoms. When one or more residents in a ward tested positive for SARS-CoV-2 infection, all other ward residents were screened for SARS-CoV-2 infection during surveillance rounds. Residents who tested positive for SARS-CoV-2 RNA were eligible for inclusion in the outbreak investigation within 8 days since the onset of symptoms or within 8 days since the first positive surveillance test result. Only patients in isolation from somatic wards were included. Oral informed consent was obtained from patients and/or from an authorised legal representative or family member.

\section{Collection of air samples}

Air samples were collected at three locations in the patient's room: 1) near the head of the patients within approximately 0.5 meter of the patient, 2) near the feet of bedridden patients approximately 1.5 meters from the head or approximately 1.5 meters from mobile patients sitting in a chair, and 3) near the location often used by healthcare workers more than 2 meters away from the patient such as the sink, all positioned at $1.5 \mathrm{~m}$ height. In every patient room, 6 -hr inhalable dust samples were taken using a filtration-based technique at all three locations (Conical Inhalable dust Sampler (CIS), JS Holdings, UK). In addition, one 6-hr two-stage cyclone-based sample with filter back-up was positioned near the feet of the patient when bedridden or at 1.5 meters from the chair of the patient (NIOSH BC 251, kindly provided by Dr William G Lindsley, NIOSH CDC, Morgantown, USA), as well as a 1-hr impingement-based sampler positioned in proximity of the head of the patient $(5 \mathrm{ml}$ BioSampler, SKC, UK) (See supplement Figure S1). During the 6-hour sample collection, mobile patients were allowed to move in the room. During the 1-hour impingement-based sample collection, they were asked to stay seated in their chair. The filtration-based sampler was equipped with a $37 \mathrm{~mm}$ diameter $2.0 \mu \mathrm{m}$ pore-size Teflon filter (Pall incorporated, Ann Arbor, USA). The two- 
stage cyclone-based sampler allowed size-selective sampling and was equipped with two conical tubes (of $15 \mathrm{ml}$ and $1.5 \mathrm{ml}$ ) which sample respectively particulates of $1-4 \mu \mathrm{m}$ and $>4 \mu \mathrm{m}$, and a backup Teflon filter (37 mm diameter $2.0 \mu \mathrm{m}$ pore-size Pall incorporated, Ann Arbor, USA) for particulates of $<1 \mu \mathrm{m}$ when operated at a flow of $3.5 \mathrm{~L} / \mathrm{min}$. The $15 \mathrm{ml}$ and $1.5 \mathrm{ml}$ conical tubes were filled with virus transport medium 1 (VTM-1; Erasmus Medical Center (EMC), Rotterdam, The Netherlands) during sampling and Opti-MeM ${ }^{\mathrm{TM}}$ (Gibco, UK) was added immediately after collection (see supplementary methods for more details and composition of media). Adding VTM-1 is a modification of the standard operating procedure for this sampler with the aim to enhance culturability of the virus. The impingement-based sampler contained VTM-1 during sampling, and after completion of sampling, Opti-MeM ${ }^{\mathrm{TM}}$ was added as well.

Airborne settling dust was sampled using Electrostatic Dust Collectors (EDCs) ${ }^{18}$, which were placed in each included patient room and the corresponding hallway, common living room, and nurse office of the ward. EDCs were placed in holders pinned to the ceiling in the middle of the space, approximately $30 \mathrm{~cm}$ underneath the ceiling or on top of a cabinet. EDCs were collected after 2-4 weeks of sampling, dependent on the timing of extensive cleaning of the room.

\section{Collection of surface samples}

High- and low-touch surface samples were collected using dry surface swabs (Medical Wire Dry Swabs, MW730, Corsham, UK) as described previously ${ }^{19,20}$. A total of ten samples were taken in each patient room, and in the corresponding hallway, common living room, and nurse office of the ward. Disposable plastic grids of $10 \mathrm{~cm}^{2}$ were used to standardise collection of surface swabs. Swabs were placed in viral transport medium 2 (VTM-2; Erasmus Medical Center (EMC), Rotterdam, The Netherlands) directly after collection (see supplementary methods for the composition of media).

Field blank samples were collected every other outbreak sampling day for each air sampling technique and every outbreak sampling day for surface swab sampling. See supplementary methods for details on sample collection and laboratory methods.

\section{Patient characteristics}

Patient characteristics were obtained: gender, year of birth, date of symptom onset, symptoms, date of SARS-CoV-2 test, SARS-CoV-2 test results, COVID-19 treatment such as oxygen therapy and mobility. An affirmative oropharyngeal swab (OPS) (Medical Wire Dry Swabs, 111598, Milano, Italy) was collected during the outbreak investigation and stored in a tube containing VTM-2. 


\section{Longitudinal air monitoring}

Three of the 28 nursing homes with at least three wards (somatic and/or geriatric) were selected for longitudinal air monitoring. In each selected nursing home, settling dust samples were collected repeatedly in three to four wards from December 2020 until May 2021. Per ward, 6 EDCs were placed in hallways, living rooms and nurse offices and renewed every four weeks for a period of four months. Incidence of SARS-COV-2 infections in patients and staff members at the included wards was obtained in weekly reports.

\section{Laboratory analysis}

All samples, except settling dust samples, were stored and send to the laboratory refrigerated at $4{ }^{\circ} \mathrm{C}$ directly after collection. At the laboratory, samples were stored at $4^{\circ} \mathrm{C}$ until further processing within 24-hours under biosafety laboratory (BSL)-2+ conditions ${ }^{21}$. Filters were removed from the filter holder and transferred to a tube containing VTM-1. These and all other outbreak investigation samples were subsequently vortexed. Settling dust samples were transferred to tubes containing VTM-2 and tamped down, vortexed and soaked repeatedly for several minutes. For RT-qPCR analysis, an aliquot of VTM was mixed in a 1:1 dilution with MagNA Pure 96 External Lysis Buffer for each sample (Roche Diagnostics, Almere the Netherlands). Remaining VTM from cyclone-based samples, impingement-based samples, surface swabs and OPS were stored for culturing. All samples were stored frozen at $-80{ }^{\circ} \mathrm{C}$ until further processing. More details are described in the supplementary methods.

\section{Real time semi-quantitative reverse transcriptase polymerase chain reaction}

VTM-lysis buffer samples were tested for presence of SARS-CoV-2 RNA using a SARS-CoV-2 RNA RTqPCR, targeting the E gene and CoV-2 RdRp-gene of SARS-CoV-2 using the cobas ${ }^{\oplus} 6800 / 8800$ Systems (Roche Diagnostics) ${ }^{22}$. If both E-gene and RdRp-gene were detected with Cobas RT-qPCR, samples were classified as positive. In case of a discrepant result, i.e. only one of the two genes was detected, an in-house RT-qPCR assay was conducted for confirmation ${ }^{23}$. In case of detection of SARS-CoV-2 RNA, the sample was classified as positive and in case of inconclusive or non-detection with in-house RT-qPCR, the final result was classified as inconclusive. Samples with non-detection of both genes were classified as negative.

Virus culture 
OPS, cyclone-based samples, impingement-based samples, and surface swabs tested positive by RTqPCR with $\mathrm{RdRp} C \mathrm{Ct} \leq 35$ were tested for infectious SARS-CoV-2, as described previously ${ }^{16}$. Virus culture was performed in 24-wells plates seeded with Vero cells, clone 118. Samples were added to the wells, centrifuged, and inoculum was discarded. Virus culture medium was added, and samples were cultured at $37^{\circ} \mathrm{C}$ and $5 \% \mathrm{CO}_{2}$ for seven days. If a virus-induced cytopathic effect (CPE) was observed, immunofluorescent detection of SARS-CoV-2 nucleocapsid protein was performed to confirm the presence of SARS-CoV-2.

\section{Data analysis}

Data entry was carried out in Microsoft Access Version 16 2012. Descriptive statistics were obtained by $R$ studio Version 1.4.1106 2021. Active air sample techniques were compared on room level. If one or more of the filtration-based samples in a room were positive, the outcome on room level was classified as positive. The same applied for the CDC-NIOSH cyclone-based samples on room level. Fisher's exact test was used to compare the proportion of positive samples in association with particle size fractions, distance and location, and to compare air sampling techniques. Agreement between outcomes of filtration-based and cyclone-based samples collected the same location was investigated through Cohen's Kappa test statistics. A threshold of 0.05 was used for the p-value for statistical significance.

\section{Results}

A total of 679 environmental samples were collected from five nursing home wards, including 101 air samples and 122 surface samples from the patient rooms and 259 air samples and 197 surface samples from common areas. In total, 13 patients were included for environmental sample collection during outbreak investigations. One patient withdrew from the study during sampling. Of the remaining 12 patients, two tested negative, and 10 tested positive in affirmative OPS collected on the day of environmental sample collection (Table 1). From one patient with negative OPS, only surface swabs were collected. For air samples, RdRp Ct-values ranged from 29.5 to 37.2 and from 30.2 to 37.8 in surface swab and from 19.8 to 34.7 in OPS. All field and laboratory blanks tested negative for viral SARS-CoV-2 RNA.

\section{SARS-CoV-2 contamination in air}

Of the 184 environmental samples collected in rooms of patients with positive OPS on the day of sampling, 50.5\% were positive (93/184). From the two patients with negative OPS, only one of the samples tested positive (1/29), which appeared a surface swab (Table 1). 
All four air sampling techniques detected SARS-CoV-2 RNA and showed high rates of positive samples in the rooms of patients with positive OPS (Table 3). The highest proportion of positive active air samples was found with the filtration-based sampler $80 \%(8 / 10)$ and CDC-NIOSH cyclonebased sampler $(70 \%(7 / 10)$. The impingement-based sampler $(50 \%(5 / 10))$ showed a slightly lower proportion of positive samples, but the results were not statistically significant (Fisher-exact test $\mathrm{p}$ value $=0.69$ ). The cyclone-based samples sampled approximately $1.26 \mathrm{~m}^{3}$ of air, the filtration-based samples $1.26 \mathrm{~m}^{3}$ and the impingement-based $0.75 \mathrm{~m}^{3}$. Ten of the collected 12 settling dust samples from rooms were positive (83\%). Filtration-based samples and cyclone-based samples collected sideby-side at the same distance from the patient were concordant in 8 out of 10 cases (moderate agreement (Cohen's kappa coefficient kappa $=0.5$, p-value=0.197)) (Supplement Table S4).

SARS-CoV-2 was detected at all distances from the patient. No clear trend was seen in numbers of positive samples with distance from the patient in filtration-based air samples (>1.5m 50\% (6/12); $\leq 1.5 \mathrm{~m}$ 67\% (10/15)) (Fisher-exact test, $\mathrm{p}$-value=0.4175) (Supplement Table S3).

In all particle size-specific fractions ( $>4 \mu \mathrm{m} 60 \%(6 / 10) ; 1-4 \mu \mathrm{m} 50 \%(5 / 10) ;<1 \mu \mathrm{m} 20 \%(2 / 10)$ SARSCoV-2 RNA was detected (Table 2). However, inconclusive and positive results were more frequently present in the largest particle size fraction, followed by the intermediate size fraction. These differences in distribution of size categories was borderline statistically significant (Fischer exact test p-value=0.076).

\section{High- and low-touch surface swabs}

The proportion of positive surface samples was much higher in rooms from patients with positive OPS compared to rooms with negative patients (43\% (43/99) versus 0,5\% (1/20)) (see Supplement Table S5). SARS-CoV-2 RNA was detected slightly more frequently in surface swabs from low-touch surfaces than from high-touch surfaces (low 50\% (22/44); high 38\% (21/55)) (Fisher's exact test pvalue $=0.18$ ). Only 5 of the 197 surface samples collected in common areas were positive for SARSCoV-2; four low and one high-touch sample (Supplement Table S6).

\section{Virus culture}

Among the 78 positive OPS, cyclone-based samples, impingement-based samples, surface swab samples, 44 had a RdRp Ct-value $\leq 35$ and were further investigated by in vitro virus culture. This selection contained four impingement-based samples, three cyclone-based samples fraction size $>4$ $\mu \mathrm{m}$, three cyclone-based samples fraction size 1-4 $\mu \mathrm{m}, 26$ surface swabs and eight OPS collected in nine patient rooms. The impingement-based samples and cyclone-based samples were collected in four patient rooms. Cytopathic effects were observed in three OPS and one active air sample and 
were confirmed by immunofluorescent staining. The active air sample from the CDC-NIOSH sampler ( $>4 \mu \mathrm{m}$ size fraction) had the lowest Ct-value of all environmental samples (29.5) and was derived from the room of the patient with the lowest OPS Ct-value (19.82).

\section{Whole genome sequencing (WGS)}

In total, nine samples with RdRp Ct-values ranging from 19.8 to 30.2 were selected for SARS-CoV-2 whole-genome sequencing, of which six OPS, one cyclone-based sample, one filtration-based sample and one surface swab. From five OPS samples, $>90 \%$ of the reference was covered and uploaded in GISAID. All variants were B.1.221, a known variant, circulating in the Netherlands at the time of the study. Samples collected at the same location were closely genetically related. During the data collection from December 2020 until May 2021, B.1.1.7, also known as the Alpha variant, became the dominant SARS-CoV-2 circulating variant in the Netherlands ${ }^{24}$. The sequences have been registered in GISAID (www.gisaid.org; Accession ID EPI_ISL_2259112, EPI_ISL_2259136, EPI_ISL_2259188). See supplementary for more details and acknowledgement table.

\section{Longitudinal air monitoring}

Only seven of the 259 settling dust samples collected repeatedly in three wards were positive (2.7\%). All samples were collected in common areas in nursing homes where SARS-CoV-2 infections had been reported among residents (Supplement Table S7). The low rate corroborates with the incidence of infections in patients and healthcare workers, which rapidly decreased during the study (Table S7). No viral RNA was detected in wards without registered SARS-CoV-2 infected patients and/or healthcare workers shortly before or during sampling.

\section{Discussion}

In this study, comprising 679 environmental samples, SARS-CoV-2 was frequently detected in air and on surfaces in the immediate surroundings of COVID-19 patients, providing evidence of virus shedding to the environment through air by infected persons. SARS-CoV-2 was detected more frequently in the particle size fraction $1-4 \mu \mathrm{m}$ (respirable fraction) and particulates $>4 \mu \mathrm{m}$ as compared to $<1 \mu \mathrm{m}$. Airborne particulates might be infectious, as illustrated by the fact that we were able to replicate virus from an active air sample. Our results support the role of airborne transmission of SARS-CoV-2, which in turn is a risk factor for subsequent infection.

SARS-CoV-2 RNA was detected in all types of air samples and on high and low-touch surfaces in the surrounding of patients with a positive OPS. No SARS-CoV-2 RNA was detected in air or the 
immediate surroundings of patients who tested negative. The number of positive environmental samples in this study was high compared to other studies ${ }^{1,25}$. Although the study size is small to modest, environmental sampling was performed extensively around patients in early phase of infection, assuming active shedding of SARS-CoV-2. Previously, Van Beek et al., established a shedding curve using data from 223 persons testing SARS-CoV-2 in a drive-through test station, showing that viral loads were highest within eight days post onset of symptoms ${ }^{15}$. Moreover, Van Kampen et al., reported that infectious virus shedding also occurred mainly within the first eight days post-onset, based on data from 129 hospitalised patients with repeated measurements ${ }^{16}$. Therefore, our study's timing of environmental measurements has likely contributed to the high detection rate in environmental samples. This is in agreement with a study from Chia et al. only detecting SARS-CoV-2 in air or the immediate surroundings of two patients infected less than eight days compared to no detection of SARS-CoV-2 in the air of another patient nine days post-infection

${ }^{4}$. Several other studies were not able to detect SARS-CoV-2 in air in the surrounding of patients more than eight days after post-onset of symptoms ${ }^{4,25,26}$. Also, studies in non-healthcare settings without patients in the early phase of infection, such as in secondary schools in the aftermath of SARS-CoV-2 associated outbreaks, were not able the measure detectable levels of SARS-CoV-2 RNA (personal communication Dr. Wouters, 2021). However, SARS-CoV-2 was detected in great abundance in surroundings from infectious minks in acute phase in mink farms ${ }^{19}$. These observations emphasize that timing of sampling in the direct environment of patients and other populations is of importance for detecting SARS-CoV-2.

Of the SARS-CoV- 2 containing aerosols, $54 \%$ was in the size range $<4 \mu \mathrm{m}$ and $46 \%$ in the size range of $\geq 4 \mu \mathrm{m}$. When including samples with inconclusive $\mathrm{qPCR}$ test results, these figures hardly changed (50\%-50\%). Although the use of the NIOSH sampler was modified by adding VTM to the vials prior to sampling, which may theoretically have altered size-selective sampling characteristics, our results are in line with other studies that performed size-selective sampling of SARS-CoV-2 virus. For instance, Adenaiye et al., analysed SARS-CoV-2 virus in exhaled breath collected from 49 COVID-19 cases (mean days post-onset $3.8 \pm 2.1$ ) in an experimental setting and found SARS-CoV-2 RNA in $36 \%$ of fine $(\leq 5 \mu \mathrm{m})$, and $26 \%$ of coarse $(>5 \mu \mathrm{m})$ aerosols ${ }^{27}$. Moreover, other studies using the same CDCNIOSH bio-sampler methodology as this study, exclusively detected SARS-CoV- 2 in the larger $\geq 4 \mu \mathrm{m}$ and intermediate size fraction $1-4 \mu \mathrm{m}$ in environmental samples collected in rooms of COVID-19 patients in hospitals ${ }^{4,5}$. Similar observations in size distribution have been reported previously for human influenza virus ${ }^{28,29}$. These results for different viruses from infected patients indicate that a substantial part of particulates is found in the respirable fraction ${ }^{28}$. Viral RNA loads and infectious 
viral RNA loads can differ between patients and are likely influenced by infection status and disease progression. Moreover, the strain-specific viral load and the location of infection in airways influence the particle size distribution and transmission mode to the environment. A different variant, such as Omikron, which is more contagious and is primarily present in the upper respiratory tract, might therefore distribute differently in the environment ${ }^{30}$.

Out of ten active air samples eligible for culture, we were able to replicate virus from one sample. Only a few studies successfully showed signs of SARS-CoV-2 replication in air samples ${ }^{1,8,27}$. However, underestimation of infectiousness is a likely consequence of virus inactivation during sample collection ${ }^{29}$. Current culture techniques may not be optimal for low viral concentrations as in air samples ${ }^{31}$. Overall, results suggest that virus particulates can cause infection in individuals who inhale these particulates when the infectious dose is sufficiently high.

Literature on the infectious dose of SARS-CoV-2 is scarce. Dabisch et al. reported an infectious dose of $52 \mathrm{TCID}_{50}$ for a seroconversion response and $256 \mathrm{TCID}_{50}$ for a fever response based on an inhalation exposure of 10 minutes in non-human primates Macaques ${ }^{32}$. Others have estimated an infectious dose for infection ranging between single and 1000 virions based on a model combining information on viral mutations obtained through deep sequencing and epidemiology in known infector-infectee pairs ${ }^{33-35}$. Based on the estimated relationship between E-gene RT-PCR Cq values and cell-cultured SARS-CoV-2 virus loads by Schuijt et al., the air sample which showed replication in our study contained approximately 170000 viral copies per cubic meter of air ${ }^{36}$. Despite uncertainties associated with this simple calculation (for instance, assuming similarity in RT-qPCR responses between cell-cultured virus and air samples), the estimated dose may indeed be capable of causing infection. Moreover, our measurements took place during relatively long periods. Environmental levels likely varied considerably over the sampling period. Variation in viral load could not be established over this time span. However, it is unlikely that viral shedding is constant over time. Coughing, for instance, results in higher viral RNA loads over a short time span.

There is an ongoing debate on the airborne transmission route of SARS-CoV- 2 and the effect of ventilation on airborne transmission. Greenhalg et al. previously pointed out multiple reasons for airborne transmission as the main route of SARS-CoV-2 ${ }^{37}$, to which our study provides additional strength. First, our study detected SARS-CoV-2 in abundance in air and on surfaces, including numerous low-touch surfaces such as on top of the wardrobe, which implicates viral dissemination through the air by aerosols. Second, SARS-CoV-2 was primarily found in particle size fractions of 1$4 \mu \mathrm{m}$ and larger than $4 \mu \mathrm{m}$, which are known to stay airborne for extended periods of time and thus 
disseminate potentially over larger distances. Third, we successfully cultured SARS-CoV-2 from an active air sample from particle size $>4 \mu \mathrm{m}$ and aerosols have been reported to stay infectious in the air for up to 3 hours ${ }^{38}$.

Based on our study, ultra-fine particles $(<1 \mu \mathrm{m})$, which can travel further, do not seem to be the key vehicle of SARS-CoV-2 transmission. Although virus contamination was omnipresent in air in infected patient rooms, the vast majority of settling dust and surface swab samples from common areas were negative, suggesting SARS-CoV-2 transmission is more a local phenomenon than widespread. To mitigate (occupational) transmission risks, it is important to investigate the effect of ventilation and air filtration on airborne transmission reduction. To date, only Morris et al. investigated and successfully demonstrated removal of SARS-CoV-2 from air by placing active filtration and sterilisation devices in wards ${ }^{5}$. Further research on the effect of ventilation and filtration devices is required to draw strong conclusions about the role of ventilation conditions in reducing airborne transmission.

In conclusion, we gained insight into the extent of SARS-CoV-2 presence in air and on surfaces in case of actively shedding patients. Furthermore, the environmental contamination of SARS-CoV-2 and infectious aerosols confirm the potential for transmission via air up to several meters. These insights can contribute to the discussion on airborne transmission and facilitate effective design of prevention strategies such as use of facemasks and optimising ventilation conditions. 
medRxiv preprint doi: https://doi.org/10.1101/2022.02.16.22271053; this version posted February 25, 2022. The copyright holder for this preprint

(which was not certified by peer review) is the author/funder, who has granted medRxiv a license to display the preprint in perpetuity.

All rights reserved. No reuse allowed without permission.

\section{Acknowledgements}

We thank the patients and healthcare workers for their cooperation and in particular Michelle van Wanrooij and Adrie de Laat from the overarching healthcare organisation Mijzo Waalwijk for their commitment and contribution. We further thank our colleagues Daan Cohen, Calvin Gue, Kees Meliefste, Duco Ottevanger, Santiago Parga, Myrna de Rooij, Peter Scherpenisse and Wouter van der Hoef from Institute Risk Assessment, Lennie Derde and Etienne Sluis from the University Medical Center Utrecht for their contribution in optimalisation of air sampling, laboratorial preparations and sample processing, and Microvida location Amphia Roosendaal and Department of Viroscience of Erasmus MC Rotterdam for further analysis of the samples. Moreover, we thank Dr. Lindsley from National Institute for Occupational Safety and Health Morgentown for the CDC-NIOSCH bio-samplers for their assistance in the pilot study. This study is funded by ZonMw and part of Control of COVID-19 iN Hospitals (COCON) consortium which also involves Rosa van Mansfeld, Karin-Ellen Veldkamp, Andreas Voss and Herman Wunderink. 


\section{References}

1. Lednicky, J. A. et al. Viable SARS-CoV-2 in the air of a hospital room with COVID-19 patients. International Journal of Infectious Diseases 100, 476-482 (2020).

2. Sikkema, R. S. et al. COVID-19 in health-care workers in three hospitals in the south of the Netherlands: a cross-sectional study. The Lancet Infectious Diseases 20, 1273-1280 (2020).

3. Cherrie, J. W. et al. Contamination of Air and Surfaces in Workplaces with SARS-CoV-2 Virus: A Systematic Review. Annals of work exposures and health 65, 879-892 (2021).

4. Chia, P. Y. et al. Detection of air and surface contamination by SARS-CoV-2 in hospital rooms of infected patients. Nature Communications 11, (2020).

5. Conway-Morris Phd, A. et al. The removal of airborne SARS-CoV-2 and other microbial bioaerosols by air filtration on COVID-19 surge units. medRixiv (2021) doi:10.1101/2021.09.16.21263684.

6. Guo, Z. D. et al. Aerosol and Surface Distribution of Severe Acute Respiratory Syndrome Coronavirus 2 in Hospital Wards, Wuhan, China, 2020. Emerging Infectious Diseases 26, 1586-1591 (2020).

7. Liu, Y. et al. Aerodynamic analysis of SARS-CoV-2 in two Wuhan hospitals. Nature 582, 557560 (2020).

8. Santarpia, J. L. et al. Aerosol and surface contamination of SARS-CoV-2 observed in quarantine and isolation care. Scientific Reports 10, (2020).

9. Faridi, S. et al. A field indoor air measurement of SARS-CoV-2 in the patient rooms of the largest hospital in Iran. Science of the Total Environment 725, (2020).

10. Lane, M. A. et al. Bioaerosol Sampling for Severe Acute Respiratory Syndrome Coronavirus 2 (SARS-CoV-2) in a Referral Center with Critically III Coronavirus Disease 2019 (COVID-19) Patients March-May 2020. Clinical infectious diseases?: an official publication of the Infectious Diseases Society of America 73, e1790-e1794 (2021).

11. Masoumbeigi, H. et al. Investigation of hospital indoor air quality for the presence of SARSCov-2. (2020) doi:10.1007/s40201-020-00543-3/Published.

12. Vosoughi, M. et al. Investigation of SARS-CoV-2 in hospital indoor air of COVID-19 patients' ward with impinger method. Environmental Science and Pollution Research 28, 50480-50488 (2021).

13. Döhla, M. et al. SARS-CoV-2 in environmental samples of quarantined households. medRxiv (2020) doi:10.1101/2020.05.28.20114041.

14. Nannu Shankar, S. et al. SARS-CoV-2 in residential rooms of two self-isolating persons with COVID-19. Journal of Aerosol Science 159, (2022).

15. van Beek, J., Igloi, Z., Boelsums, T., Fanoy, E. \& Gotz, H. From more testing to smart testing data-guided SARS-CoV-2 testing choices. medRxiv (2020).

16. van Kampen, J. J. A. et al. Duration and key determinants of infectious virus shedding in hospitalized patients with coronavirus disease-2019 (COVID-19). Nature Communications 12, (2021).

17. National Institute for Public Health and the Environment, T. N. Coronadashboard. https://coronadashboard. rijksoverheid.nl/landelijk/verpleeghuiszorg (2021).

18. Noss, l. et al. Evaluation of a low-cost electrostatic dust fall collector for indoor air endotoxin exposure assessment. Applied and Environmental Microbiology 74, 5621-5627 (2008).

19. de Rooij, M. M. T. et al. Occupational and environmental exposure to SARS-CoV-2 in and around infected mink farms. Occupational and Environmental Medicine (2021) doi:10.1101/2021.01.06.20248760.

20. WHO \& World Health Organization. Surface sampling of coronavirus disease (COVID-19): A practical "how to" protocol for health care and public health professionals. (2020).

21. Duane, E. G. A Practical Guide to Implementing a BSL-2+ Biosafety Program in a Research Laboratory. Applied Biosafety 18, (2013). 
22. Stohr, J. J. J. M. et al. Clinical performance and sample freeze-thaw stability of the cobas ${ }^{\oplus} 6800$ SARS-CoV-2 assay for the detection of SARS-CoV-2 in oro-/nasopharyngeal swabs and lower respiratory specimens. Journal of Clinical Virology 133, (2020).

23. Kluytmans-Van Den Bergh, M. F. Q. et al. Prevalence and Clinical Presentation of Health Care Workers with Symptoms of Coronavirus Disease 2019 in 2 Dutch Hospitals during an Early Phase of the Pandemic. JAMA Network Open 3, (2020).

24. National Institute for Public Health and the Environment, T. N. Varianten van het coronavirus SARS-CoV-2. https://www.rivm.nl/coronavirus-covid-19/virus/varianten (2022).

25. Semelka, C. T. et al. Detection of Environmental Spread of SARS-CoV-2 and Associated Patient Characteristics. Open Forum Infectious Diseases 8, (2021).

26. Dumont-Leblond, N. et al. Positive no-touch surfaces and undetectable SARS-CoV-2 aerosols in long-term care facilities: An attempt to understand the contributing factors and the importance of timing in air sampling campaigns. American Journal of Infection Control 49, 701-706 (2021).

27. Adenaiye, O. O. et al. Infectious Severe Acute Respiratory Syndrome Coronavirus 2 (SARS(oV-2) in Exhaled Aerosols and Efficacy of Masks During Early Mild Infection. Clinical Infectious Diseases (2021) doi:10.1093/cid/ciab797.

28. Blachere, F. M. et al. Measurement of airborne influenza virus in a hospital emergency department. Clinical Infectious Diseases 48, 438-440 (2009).

29. Lindsley, W. G. et al. Measurements of airborne influenza virus in aerosol particles from human coughs. PLOS ONE 5, (2010).

30. Vihta, K.-D., Pouwels, K. B. \& Peto, T. E. Omicron-associated changes in SARS-CoV-2 symptoms in the united kingdom. medRxiv (2022).

31. Zhang, X. S. et al. SARS-CoV-2 and Health Care Worker Protection in Low-Risk Settings: a Review of Modes of Transmission and a Novel Airborne Model Involving Inhalable Particles. (2020) doi:10.1128/CMR.

32. Dabisch, P. A. et al. Seroconversion and fever are dosepependent in a nonhuman primate model of inhalational COVID-19. PLoS Pathogens 17, (2021).

33. Popa, A. et al. Genomic epidemiology of superspreading events in Austria reveals mutational dynamics and transmission properties of SARS-CoV-2. Sci. Transl. Med vol. 12 https://www.science.org (2020).

34. Martin, M. A. \& Koelle, K. Comment on "Genomic epidemiology of superspreading events in Austria reveals mutational dynamics and transmission properties of SARS-CoV-2." Sci. Transl. Med 13, 1803 (2021).

35. Nicholson, M. D. et al. Response to comment on "Genomic epidemiology of superspreading events in Austria reveals mutational dynamics and transmission properties of SARS-CoV-2." Science Translational Medicine 13, (2021).

36. Schuit, E. et al. Supplementary Appendix of Diagnostic accuracy of rapid antigen tests in asymptomatic and presymptomatic close 3 contacts of individuals with confirmed SARS-CoV2 infection: cross sectional study. The BMJ (2021).

37. Greenhalgh, T. et al. Ten scientific reasons in support of airborne transmission of SARS-CoV-2. The Lancet 397, 1603-1605 (2021).

38. van Doremalen, N., Bushmaker, T. \& Morris, D. Aerosol and Surface Stability of SARS-CoV-2 as Compared with SARS-CoV-1. The new england journal of medicine (2020).

39. O'Toole, Á. et al. Assignment of epidemiological lineages in an emerging pandemic using the pangolin tool. Virus Evolution 7, (2021).

40. Elbe, S. \& Buckland-Merrett, G. Data, disease and diplomacy: GISAID's innovative contribution to global health. Global Challenges 1, 33-46 (2017).

41. Katoh, K. \& Standley, D. M. MAFFT multiple sequence alignment software version 7: Improvements in performance and usability. Molecular Biology and Evolution 30, 772-780 (2013). 
medRxiv preprint doi: https://doi.org/10.1101/2022.02.16.22271053; this version posted February 25, 2022. The copyright holder for this preprint

(which was not certified by peer review) is the author/funder, who has granted medRxiv a license to display the preprint in perpetuity.

All rights reserved. No reuse allowed without permission.

42. Minh, B. Q. et al. IQ-TREE 2: New Models and Efficient Methods for Phylogenetic Inference in the Genomic Era. Molecular Biology and Evolution 37, 1530-1534 (2020).

43. Minh, B. Q., Nguyen, M. A. T. \& von Haeseler, A. Ultrafast approximation for phylogenetic bootstrap. Molecular Biology and Evolution 30, 1188-1195 (2013).

44. Kalyaanamoorthy, S., Minh, B. Q., Wong, T. K. F., von Haeseler, A. \& Jermiin, L. S. ModelFinder: Fast model selection for accurate phylogenetic estimates. Nature Methods 14, 587-589 (2017). 
medRxiv preprint doi: https://doi.org/10.1101/2022.02.16.22271053; this version posted February 25, 2022. The copyright holder for this preprint (which was not certified by peer review) is the author/funder, who has granted medRxiv a license to display the preprint in perpetuity. All rights reserved. No reuse allowed without permission.

\section{Outbreak investigation}

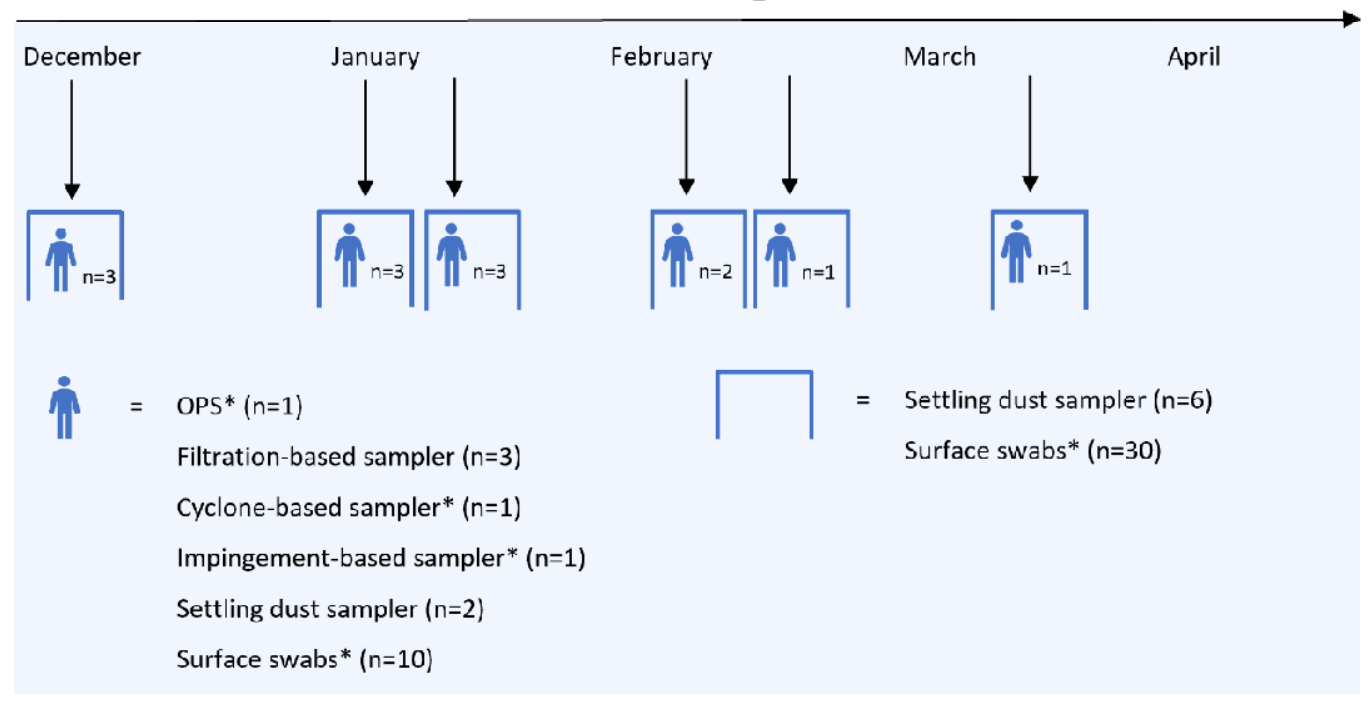

Longitudinal alr monitoring

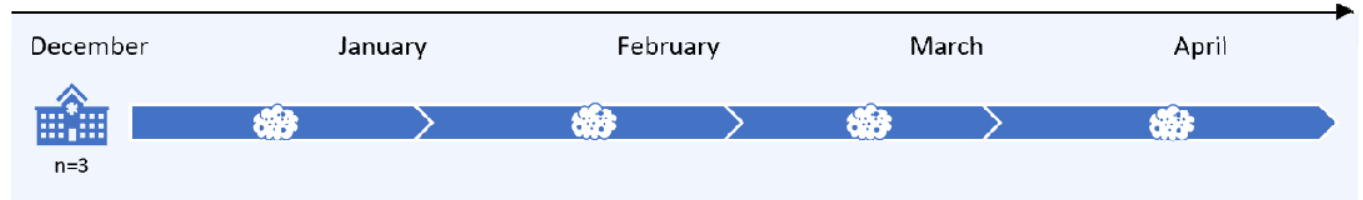
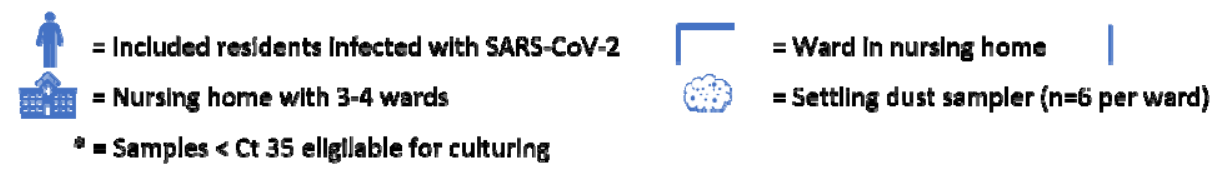

Figure 1: Design of the study. The study consisted of an outbreak investigation which was complemented by longitudinal air monitoring. 
Table 1: SARS-CoV-2 PCR in environmental samples in the surrounding of isolated patients and common areas in nursing homes

\begin{tabular}{|c|c|c|c|c|c|c|c|c|c|c|c|}
\hline \multirow[b]{4}{*}{ Outbreak } & \multirow[b]{4}{*}{ Location } & \multicolumn{3}{|c|}{ Patient characteristics } & \multicolumn{7}{|c|}{ Environmental samples } \\
\hline & & \multirow{3}{*}{$\begin{array}{l}\text { Day of } \\
\text { illness }\end{array}$} & \multirow{3}{*}{ Mobility } & \multirow{3}{*}{$\begin{array}{c}\text { Oropharyngea } \\
\text { I swab } \\
\text { (RdRp CT) }\end{array}$} & \multicolumn{5}{|c|}{ Active air sampling } & \multicolumn{2}{|c|}{ Passive (air) sampling } \\
\hline & & & & & \multirow{2}{*}{$\begin{array}{c}\begin{array}{c}\text { CIS - } \\
\text { in halable } \\
\text { dust }\end{array} \\
\text { PTFE filter }\end{array}$} & \multicolumn{3}{|c|}{$\begin{array}{l}\text { CDC-NIOSH bioaerosol sampler - } \\
\text { cyclone-based }\end{array}$} & \multirow[t]{2}{*}{$\begin{array}{l}\text { SKC Bio- } \\
\text { sampler - } \\
\text { Impinger }\end{array}$} & \multirow[t]{2}{*}{$\begin{array}{c}\text { EDC - } \\
\text { settling dust }\end{array}$} & \multirow[t]{2}{*}{$\begin{array}{l}\text { Surface } \\
\text { swabs }\end{array}$} \\
\hline & & & & & & $\begin{array}{l}\text { filter } \\
(<1 \\
\mu \mathrm{m})\end{array}$ & $\begin{array}{c}\text { tube } \\
1.5 \mathrm{ml} \\
(1-4 \mu \mathrm{m})\end{array}$ & $\begin{array}{l}\text { tube } \\
15 \mathrm{ml} \\
(>4 \mu \mathrm{m})\end{array}$ & & & \\
\hline \multirow[t]{4}{*}{$A$} & Patient room 10 & 4 & No & $19.8^{C}$ & $3 / 0 / 0$ & $1 / 0 / 0$ & $1 / 0 / 0$ & $1 / 0 / 0^{c}$ & $1 / 0 / 0$ & NO & $4 / 1 / 5$ \\
\hline & Patient room $11^{x}$ & 6 & Yes & neg & NO & NO & NO & NO & NO & $0 / 1 / 0$ & $1 / 0 / 9$ \\
\hline & Patient room 12 & 7 & $\mathrm{No}^{\mathrm{ox}}$ & 29.6 & $2 / 1 / 0$ & $0 / 0 / 1$ & $1 / 0 / 0$ & $0 / 1 / 0$ & $0 / 0 / 1$ & NO & $3 / 0 / 6$ \\
\hline & Common areas & - & - & - & - & - & - & - & - & $2 / 1 / 3$ & $0 / 0 / 20 *$ \\
\hline \multirow[t]{4}{*}{$B_{1}$} & Patient room 13 & 1 & No ${ }^{\mathrm{X}}$ & $27.6^{c}$ & $3 / 0 / 0$ & $0 / 0 / 1$ & $1 / 0 / 0$ & $1 / 0 / 0$ & $1 / 0 / 0$ & $1 / 0 / 0$ & $9 / 0 / 1$ \\
\hline & Patient room 14 & AS & Yes & neg & $0 / 0 / 3$ & $0 / 0 / 1$ & $0 / 0 / 1$ & $0 / 0 / 1$ & $0 / 0 / 1$ & $0 / 1 / 1$ & $0 / 0 / 10$ \\
\hline & Patient room 15 & Unclear & Yes & 29.7 & $0 / 0 / 3$ & $0 / 0 / 1$ & $0 / 0 / 1$ & $0 / 0 / 1$ & $1 / 0 / 0$ & $1 / 0 / 0$ & $5 / 1 / 4$ \\
\hline & Common areas & - & - & - & - & - & - & - & - & $3 / 0 / 2$ & $0 / 0 / 30$ \\
\hline \multirow[t]{4}{*}{$B_{2}$} & Patient room 16 & AS & Yes & 32.8 & $2 / 0 / 1$ & $0 / 0 / 1$ & $0 / 0 / 1$ & $1 / 0 / 0$ & $0 / 0 / 1$ & $2 / 0 / 0$ & $4 / 0 / 6$ \\
\hline & Patient room 17 & AS & Yes & $19.9^{c}$ & $3 / 0 / 0$ & $1 / 0 / 0$ & $1 / 0 / 0$ & $1 / 0 / 0$ & $1 / 0 / 0$ & $2 / 0 / 0$ & $5 / 1 / 4$ \\
\hline & Patient room 18 & 1 & Yes & 33.6 & $2 / 0 / 1$ & $0 / 0 / 1$ & $0 / 0 / 1$ & $1 / 0 / 0$ & $0 / 0 / 1$ & $1 / 0 / 1$ & $4 / 0 / 6$ \\
\hline & Common areas & - & - & - & - & - & - & - & - & $3 / 0 / 2$ & $4 / 0 / 26$ \\
\hline \multirow[t]{4}{*}{$C^{* *}$} & Patient room $19^{x}$ & 5 & Yes & NO & $0 / 0 / 3$ & $0 / 0 / 1^{\circledR}$ & $0 / 0 / 1^{1}$ & 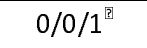 & NO & $0 / 0 / 2$ & NO \\
\hline & Common areas & - & - & - & - & - & - & - & - & NO & $0 / 0 / 30$ \\
\hline & Patient room 20 & 5 & Yes & 34.7 & $3 / 0 / 0$ & $0 / 0 / 1$ & $1 / 0 / 0$ & $1 / 0 / 0$ & $1 / 0 / 0$ & $2 / 0 / 0$ & $12 / 0 / 1^{* * *}$ \\
\hline & Common areas & - & - & - & - & - & - & - & - & NO & $1 / 0 / 26$ \\
\hline \multirow[t]{2}{*}{$D$} & Patient room 22 & 3 & $\mathrm{No}^{\mathrm{OX}}$ & 30.8 & $1 / 0 / 2$ & $0 / 0 / 1$ & $0 / 0 / 1$ & $0 / 0 / 1$ & $0 / 0 / 1$ & $0 / 0 / 1$ & $0 / 0 / 10$ \\
\hline & Common areas & - & - & - & - & - & - & - & - & $0 / 0 / 5$ & $0 / 0 / 30$ \\
\hline \multirow[t]{2}{*}{$E$} & Patient room $25^{\vee}$ & 6 & Yes & 33.5 & $0 / 1 / 2$ & $0 / 0 / 1$ & $0 / 1 / 0$ & $0 / 1 / 0$ & $0 / 1 / 0$ & $1 / 0 / 0$ & $0 / 1 / 9$ \\
\hline & Common areas & - & - & - & - & - & - & - & - & $0 / 0 / 6$ & $0 / 0 / 30$ \\
\hline
\end{tabular}

SARS-CoV-2 results from environmental samples: Number of positive/inconclusive/negative. All positive samples from PCR are cultured from oropharyngeal swab, CDC-NIOSH bioaerosol sampler, SKC Bio-sampler and surfaces wabs. Day of illness is counted since onset of symptoms. In case planned samples were not obtained the following reasons applied: retraction patient, no availability or accessibility of area during sample collection, sample got lost or discarded by staff. * = living room was not available for sampling due to closure $/ * *=$ two patients on

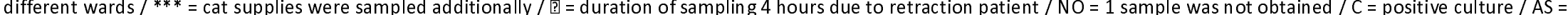
asymptomatic $/ \mathrm{OX}=$ optiflow $/ \mathrm{V}=$ vaccinated. In total 27 samples were not obtained because of retraction patient, no availability of area during sample collection or discarded by staff. 
medRxiv preprint doi: https://doi.org/10.1101/2022.02.16.22271053; this version posted February 25, 2022. The copyright holder for this preprint (which was not certified by peer review) is the author/funder, who has granted medRxiv a license to display the preprint in perpetuity.

All rights reserved. No reuse allowed without permission.

Table 2: SARS-CoV-2 PCR results in size specific fractions obtained by cyclone-based air sampling in rooms of patients with positive oropharyngeal swab.

\begin{tabular}{|c|c|c|c|}
\hline \multirow{2}{*}{} & \multicolumn{2}{|c|}{ CDC-NIOSH cyclone-based bioaerosol sampler } \\
\cline { 2 - 4 } & $<1 \mu \mathrm{m}$ & $\mathbf{1 - 4} \boldsymbol{\mu \mathrm { m }}$ & $>\mathbf{\mu m}$ \\
& PTFE filter & Microcentrifuge tube 1.5 ml & Centrifuge tube 15 ml \\
& $n$ & $n$ & $n$ \\
\hline Negative (- & 8 & 4 & 2 \\
Inconclusive (-+) & 0 & 1 & 6 \\
Positive (++) & 2 & 5 & 2 \\
\hline
\end{tabular}

Table 3: SARS-CoV-2 results from three active and one passive air sampling technique used during the outbreak investigation from patients with positive oropharyngeal swab.

\begin{tabular}{|c|c|c|c|c|}
\hline & $\begin{array}{c}\text { CIS - } \\
\text { inhalable dust }\end{array}$ & $\begin{array}{c}\text { SKC Bio-sampler - } \\
\text { Impinger } \\
n(\%)\end{array}$ & $\begin{array}{c}\text { CDC-NIOSH cyclone- } \\
\text { based bioaerosol * }\end{array}$ & $\begin{array}{c}\text { EDC - } \\
\text { settling dust } \\
n(\%)\end{array}$ \\
\hline Negative (- -) & $9(30)$ & $4(40)$ & $2(20)$ & $2(17)$ \\
Inconclusive (- +) & $2(7)$ & $1(10)$ & $1(10)$ & $0(0)$ \\
Positive (++) & $19(63)$ & $5(50)$ & $7(70)$ & $10(83)$ \\
\hline
\end{tabular}

${ }^{*}=$ if one of the fractions of the cyclone-based sample detected SARS-CoV-2, the overall parameter is classified positive. 


\section{Supplement: method and materials Outbreak investigation}

\section{Filtration-based sampler}

The filtration-based technique captures inhalable dust - airborne particles and droplets of an aerodynamic size that enter the respiratory tract through mouth and nose. Air is drawn through an inhalable dust sampling head (Conical Inhalable Sampler, JS Holdings, Stevenage, UK) equipped with $37 \mathrm{~mm}$ diameter $2.0 \mu \mathrm{m}$ pore-size Teflon filter (Pall incorporated, Ann Arbor, USA) connected with tubing to a Gilian GilAir 5 pump (Sensidyne, St. Petersburg, USA) calibrated at a flow of $3.5 \mathrm{~L} / \mathrm{min}$. The sampling head were attached to a pole at $1.5 \mathrm{~m}$ height as this is average breathing height. The sampling train was set up before the beginning of the measurement and lasted for 6 hours. In each patient room, three inhalable dust samplers were placed, one near the head of the patient, one near the feet of the patient and one near the location often used by healthcare worker (Figure S1).

\section{Cyclone-based sampler}

The cyclone-based technique allowed for size-selective sampling of dusts and aerosols from the environment. The CDC-NIOSH cyclone-based bioaerosol sampler (NIOSH BC 251, kindly provided to us by William G. Lindsley, NIOSH Morgantown, USA) consists of a sampling body which is equipped with a $15 \mathrm{ml}$ conical tube (Greiner Bio-One, Alphen aan de Rijn, Netherlands) to capture aerosols larger than $4 \mu \mathrm{m}$ in size, a $1.5 \mathrm{ml}$ conical tube (Sarstedt BV, Etten-Leur, Netherlands) to capture aerosols with a size ranging between 1-4 $\mu \mathrm{m}$, and a $37 \mathrm{~mm}$ diameter filter holder (SKC Incorporated, Eighty Four, USA) equipped with $37 \mathrm{~mm}$ diameter $2.0 \mu \mathrm{m}$ pore-size Teflon filter (Pall incorporated, Ann Arbor, USA) to collect particles of $1 \mu \mathrm{m}$ and smaller. The filter holder was connected with tubing to a Gilian GilAir 5 pump (Sensidyne, St. Petersburg, USA) calibrated at a flow of $3.5 \mathrm{~L} / \mathrm{min}$. The $15 \mathrm{ml}$ and $1.5 \mathrm{ml}$ tube were pre-filled with $2.5 \mathrm{ml}$ and $1 \mathrm{ml}$ virus transport medium 1 (VTM-1; Erasmus Medical Center (EMC), Rotterdam, The Netherlands), respectively, before start of the measurement (table S1 composition of media). The sampling train was set up before the beginning of the measurement and lasted for 6 hours. In each patient room, one cyclone sampler was placed in conjunction with one of the filtration-based samplers close to the feet of the patient. After sampling filter holders were detached, packed in a Minigrip ${ }^{\mathrm{TM}}$ bag. The $15 \mathrm{ml}$ and $1.5 \mathrm{ml}$ tubes were detached

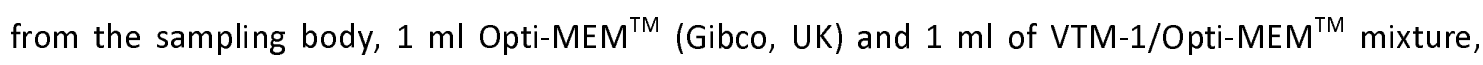
respectively, was added to the tubes immediately after sampling.

\section{Impingement-based sampler}

Air sampling through impingement was conducted by means of a $5 \mathrm{ml}$ BioSampler (SKC Inc, Eighty Four, USA) positioned at $1.5 \mathrm{~m}$ height attached to a pole. An airflow of $12.5 \mathrm{~L} / \mathrm{min}$ through the BioSampler was established by connecting the outlet of the sampler to an inhouse designed pump 
unit. The impinger was filled with $4 \mathrm{ml}$ of VTM-1 used for air sampling (see above) prior to the beginning of the measurement. The measurement lasted 1 hour close to the patient's head, during which evaporation losses of VTM was replaced by adding every 15 minutes $2 \mathrm{ml}$ of VTM-1. After sampling, remaining VTM fluid was transferred to a $15 \mathrm{ml}$ tube (Greiner BioOne, Etten-Leur, Netherlands) and $2 \mathrm{ml}$ of Opti-MEM ${ }^{\top \mathrm{M}}$ was added.

\section{Settling dust sampler}

Settling dust, passive air, samples were collected by using Electrostatic Dust Collectors (EDCs) (Noss et al., 2008), which were placed in each included patient room and corresponding hallway, common living room and nurse office of the ward. EDCs were placed in holders pinned to the ceiling in the middle of the space. After 2-4 weeks of sampling EDCs were picked up and packed in a Minigrip ${ }^{\mathrm{TM}}$ bag for transportation.

\section{Collection of surface samples}

In each of the above areas: each included patient room, hallway, living room and nursing office, ten swab samples from surfaces were collected. Sampling locations included high-touch surfaces like door handle and tabletop and low-touch surfaces like top surface of cabinets. To standardize swabbing of surfaces, disposable plastic grids of $10 \mathrm{~cm}^{2}$ were used; when it was not possible to use the grid this was noted. Dry swabs (Medical Wire Dry Swabs, MW370, Corsham, UK) were used, which were placed in $2 \mathrm{ml}$ viral transport medium 2 (VTM-2; Erasmus Medical Center (EMC), Rotterdam, The Netherlands) in $5 \mathrm{ml}$ tubes directly after swabbing (for composition of media see table S2).

\section{Patient characteristics}

Oropharyngeal swabs (OPS) was collected from patients during sample collection. Dry swabs (Medical Wire Dry Swabs, 111598, Milano, Italy) were used, which were placed in 2mI VTM-2 in 5ml tubes directly after swabbing.

\section{Laboratory analysis}

After collection, all samples, except for EDCs, were stored at $4{ }^{\circ} \mathrm{C}$ in electric transport cooling box and transported to the lab. At the lab, all samples, except for EDCs, were placed in $4^{\circ} \mathrm{C}$ storage until further processing the next day. All handlings were performed under BSL2+ conditions. In short, filters were removed from the filter holders and transferred to $5 \mathrm{ml}$ screw-top tubes (Eppendorf, Nijmegen, Netherlands) and 2ml of VTM-1 used for air sampling was added, next tubes were vortexed for 5 minutes using a vortex adaptor. Tubes containing VTM and Opti-MEM ${ }^{\text {TM }}$ mixture from 
medRxiv preprint doi: https://doi.org/10.1101/2022.02.16.22271053; this version posted February 25, 2022. The copyright holder for this preprint

(which was not certified by peer review) is the author/funder, who has granted medRxiv a license to display the preprint in perpetuity.

All rights reserved. No reuse allowed without permission.

NIOSH and impingement-based samplers and OPS were vortexed for 15 seconds, and tubes containing the surface swab samples were vortexed for $1 \mathrm{~min}$ prior to further handling. After vortexing $600 \mu \mathrm{l}$ was transferred and added to a tube containing $600 \mu \mathrm{l}$ of MagNA Pure 96 External Lysis Buffer (Roche Diagnostics, Almere the Netherlands), followed by 15 seconds of vortexing. Aliquots with remaining VTM from NIOSH, impingement, surface swab and OPS were stored frozen at $-80{ }^{\circ} \mathrm{C}$ for culturing. Aliquots with VTM/lysis buffer samples were stored frozen at $-80^{\circ} \mathrm{C}$ for PCR.

\section{Settling dust sampler}

EDCS were transferred to tube containing $10 \mathrm{ml}$ VTM-2. EDCs were tamped down with disposable pipette, followed by repeating twice 15 seconds of vortexing and soaked for 15 minutes and ended with 15 minutes of vortexing. EDCs were tamped down with disposable pipette and 600 ul sample was transferred and added to a tube containing 600 ul MagNA Pure 96 External Lysis Buffer (Roche Diagnostics, Almere the Netherlands) and followed by 15 seconds of vortexing. VTM/lysis buffer samples were stored frozen at $-80^{\circ} \mathrm{C}$.

\section{Real time quantitative $R T-P C R$}

Samples were transported on dry ice to Microvida Laboratory for Medical Microbiology, Bravis Hospital, Roosendaal, The Netherlands. Presence of SARS-CoV-2 RNA was tested using a SARS-CoV-2 RNA RT-qPCR, targeting the E gene and CoV-2 RdRP-gene of SARS-CoV-2. The cobas ${ }^{\circledR}$ SARS-CoV-2 Test (Roche Diagnostics, Basel, Switzerland) was performed on the samples with lysis buffer using the cobas ${ }^{\circledast} 6800$ Systems (Roche Diagnostics). Samples were positive if the threshold was below Ctvalue 40 .

\section{SARS-CoV-2 Whole genome sequencing (WGS)}

Samples with RT-PCR RdRp Ct-values $<31$ whole genome sequencing of the primary clinical specimen was performed by Microvida to determine the SARS-CoV-2 variant. In short, total nucleic acids were extracted using the QIAsymphony DSP virus pathogen midi kit and pathogen complex 400 protocol of the QIAsymphony Sample Processing system (Qiagen, Germany), with an input volume of $400 \mu \mathrm{L}$ and output volume of $110 \mu \mathrm{L}$. cDNA was synthesized using LunaScript ${ }^{\circledR}$ RT SuperMix Kit (New Engeland Biolabs, USA) and library preparation was performed using EasySeqTM RC-PCR SARS-CoV-2 Whole Genome Sequencing kit (Nimagen, The Netherlands) according to manufacturer's instructions. Subsequent next generation sequencing (NGS) of $2 \times 150$ cycles paired end reads was performed on a Miseq (Illumina, The Netherlands) using MiSeq Reagent Micro Kit v2 according to manufacturer's instructions. Data analyses was performed with an in-house workflow using CLCbio Genomic Workbench v21 (Qiagen, Germany), including (a.o.) read-trimming, NC_045512.2 (NCBI genbank) reference-based assembly, local re-alignment and variant detection algorithms. The 
consensus genome was extracted and positions with a coverage less than 10 reads were replaced with N. The sequences were manually curated. Genomes with $>70 \%$ genome coverage were included for lineage assignment using Pangolin (https://pangolin.cog-uk.io/) ${ }^{39}$ and Nextclade Web (https://clades.nextstrain.org/) (Hadfield et al., 2018)). Genomes with $>90 \%$ genome coverage were uploaded to GISAID (https://www.gisaid.org/) ${ }^{40}$, with accession IDs EPI_ISL_3047866, EPI_ISL_3047867, EPI_ISL_2259188, EPI_ISL_2259136 and EPI_ISL_2259122 and phylogenetic analysis performed using MAFFT alignment software (Galaxy Version 7.221.3, FFT-NS method) ${ }^{41}$ and phylogenomic software IQ-TREE 2.1.3 (Galaxy Version 1.5.5.3) ${ }^{42-44}$, using ModelFinder (with best predicted method $\mathrm{GTR}+\mathrm{F}+\mathrm{I}$ ), ultrafast bootstrapping (1000 replicates) and maximum likelihood tree reconstruction. Phylogenetic tree was visualized in CLCbio Genomic Workbench v20.

\section{Virus culture}

Positive tested samples with RT-qPCR from the OPS, cyclone-based, impingement-based and surface swabs were transported on dry ice, using the duplex aliquot without lysis buffer for culturing at Erasmus University Medical Centre laboratory, Rotterdam, the Netherlands. Culturing was performed on Vero cells, clone 118 at $37^{\circ} \mathrm{C}$, and $5 \% \mathrm{CO}_{2}$ and was completed after 7 days. If virusinduced cytopathic effect was observed, immunofluorescent detection of nucleocapsid proteins was performed to confirm the presence of SARS-CoV- $2^{16}$.

\section{Modification in sample collection}

After the first outbreak investigation outbreak $A$, an optimised protocol was implemented. For the first outbreak investigation VTM-2 was used as pre-fill in the tubes for the cyclone-based, impingement-based and re-fill for impingement sampling in instead of VTM-2. After sampling the impingement-based sampler VTM fluid was transferred to a $15 \mathrm{ml}$ tube (Greiner BioOne, Etten-Leur, Netherlands) containing 1,5 ml Fetal Bovine Serum (FSB) (40 v/v\%, Greiner Bio-One, Etten-Leur, Netherlands). Instead of adding Opti-MEM ${ }^{\mathrm{TM}}$ mixture or VTM/Opti-MEM ${ }^{\mathrm{TM}}$ mixture after sampling to the cyclone-based samples, the day after during processing only VTM-2 was added up to the original amount prior to sample collection. Sampling and processing of surface swabs, OPS and EDCs stayed identical. 


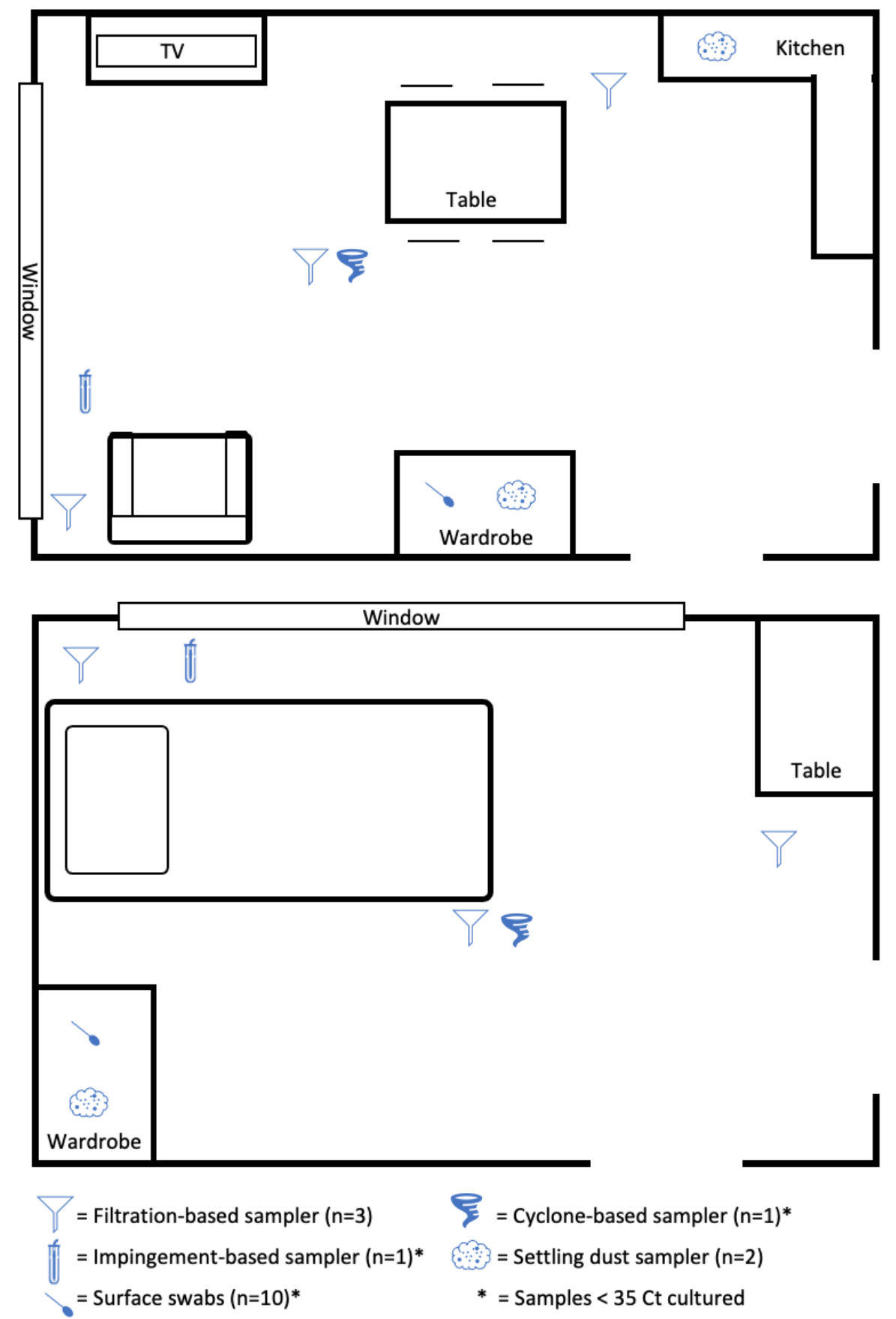

Figure S1: Illustration of sample collection in patient room. The first figure shows data collection in the living room of a mobile patient sitting in a chair. The second figure illustrates data collection in the sleeping room of a bedridden patient. 
medRxiv preprint doi: https://doi.org/10.1101/2022.02.16.22271053; this version posted February 25, 2022. The copyright holder for this preprint (which was not certified by peer review) is the author/funder, who has granted medRxiv a license to display the preprint in perpetuity.

All rights reserved. No reuse allowed without permission.

Table S1: VTM-1 composition

\begin{tabular}{|l|lll|}
\hline Name & $\begin{array}{l}\text { Volume } \\
(\mathrm{ml})\end{array}$ & Brand & Cat. Nr. \\
\hline HMEM (with 25 mM Hepes) & $4000 \mathrm{~mL}$ & Lonza/Westburg BV & LO 12-137F \\
\hline HEPES, 1M & $700 \mathrm{ml}$ & Lonza/Westburg BV & BE17-737E \\
\hline Glycerol 99\% & $480 \mathrm{ml}$ & Sigma Aldrich & G6279-1L \\
\hline $\begin{array}{l}\text { Lactalbumin enzymatic } \\
\text { hydrolysate** }\end{array}$ & $20 \mathrm{gr}$ & Sigma Aldrich & $61300-500 \mathrm{G}$ \\
\hline $\begin{array}{l}\text { Polymyxin B } \\
\text { Sulphate }(1,67 \mathrm{mg} / \mathrm{ml})\end{array}$ & $48 \mathrm{ml}$ & Sigma Aldrich & P0972-10MU \\
\hline Nystatin $(1,69 \mathrm{mg} / \mathrm{ml})$ & $24 \mathrm{ml}$ & Sigma Aldrich & N6261-5MU \\
\hline Pen/Strep $(10.000 \mathrm{U} / 10.000 \mathrm{uG})$ & $96 \mathrm{ml}$ & Westburg & LO DE17-602E \\
\hline Gentamicin & $24 \mathrm{ml}$ & Life Technologies & 15750037 \\
\hline
\end{tabular}

Table S2: VTM-2 composition

\begin{tabular}{|l|lll|}
\hline Name & $\begin{array}{l}\text { Volume } \\
(\mathrm{ml})\end{array}$ & Brand & Cat. Nr. \\
\hline $\begin{array}{l}\text { Dulbecco's Modified Eagle's } \\
\text { Medium (DMEM) } \\
\text { (without NaHCO3 Hepes, L- } \\
\text { Glutamin) }\end{array}$ & 107 & Lonza & BESP070 \\
\hline $\begin{array}{l}\text { Penicillin } / \text { Streptomycin } \\
(10000 \mathrm{U} / \mathrm{ml} ; 10000 \mu \mathrm{g} / \mathrm{ml})\end{array}$ & 25 & Lonza & $17-602 \mathrm{E}$ \\
\hline Amphotericin B $(0,25 \mathrm{mg} / \mathrm{ml})$ & 10 & Pharmacy, EMC & n.a. \\
\hline NaHCO3 & 3 & Lonza & $17-613 \mathrm{E}$ \\
\hline Hepes (1M) & 5 & Lonza & $17-737 \mathrm{E}$ \\
\hline Fetal Bovine Serum (FBS) & 100 & Greiner Bio-one & 758093 \\
\hline
\end{tabular}

\section{Supplement: Results}

Table S3: SARS-CoV-2 PCR results in inhalable dust samples collected in rooms of patients with positive OS stratified by distance to the patient

\begin{tabular}{|c|c|c|}
\hline \multirow{2}{*}{} & \multicolumn{2}{|c|}{ CIS - inhalable dust } \\
\cline { 2 - 3 } & $\mathbf{N}=\mathbf{5}$ & $>\mathbf{1 5}$ meter \\
& $5(33)$ & $\mathbf{N}=\mathbf{1 2}$ \\
\hline Negative (- $)$ & $0(0)$ & $4(33)$ \\
Inconclusive (-+) & $10(67)$ & $2(17)$ \\
Positive (++) & $6(50)$ \\
\hline
\end{tabular}

During data collection of one patient no distances were obtained $(n=3)$. 
medRxiv preprint doi: https://doi.org/10.1101/2022.02.16.22271053; this version posted February 25, 2022. The copyright holder for this preprint (which was not certified by peer review) is the author/funder, who has granted medRxiv a license to display the preprint in perpetuity.

All rights reserved. No reuse allowed without permission.

Table S4: SARS-CoV-2 PCR results in inhalable dust samples cyclone-based samples from patients with positive OS

\begin{tabular}{|l|c|c|c|}
\hline & $\begin{array}{c}\text { CIS - } \\
\text { inhalable dust }\end{array}$ & $\begin{array}{c}\text { CDC-NIOSH bioaerosol sampler - } \\
\text { cyclone-based }\end{array}$ & Distance (cm) \\
\hline Patient room 10 & ++ & ++ & NA \\
Patient room 12 & ++ & ++ & 160 \\
Patient room 13 & ++ & ++ & 100 \\
Patient room 15 & -- & +- & 210 \\
Patient room 16 & ++ & ++ & 85 \\
Patient room 17 & ++ & ++ & 74 \\
Patient room 18 & ++ & ++ & 140 \\
Patient room 20 & ++ & -- & 135 \\
Patient room 22 & ++ & -+ & 100 \\
Patient room 25 & -- & ++ & 130 \\
\hline
\end{tabular}

$V=$ fully vaccinated patient

Table S5: SARS-CoV-2 PCR results surface swab samples from patients with positive OS

\begin{tabular}{|c|c|c|}
\hline & High-touch & Low-touch \\
\hline Negative (- -) & $33(60)$ & $19(43)$ \\
Inconclusive (- +) & $1(2)$ & $3(7)$ \\
Positive (++) & $21(38)$ & $22(50)$ \\
\hline
\end{tabular}

Table S6: SARS-CoV-2 PCR results surface swab samples from common areas

\begin{tabular}{|c|c|c|}
\hline & High-touch & Low-touch \\
\hline Negative (- -) & $94(98,9)$ & $98(96)$ \\
Inconclusive (- +) & $0(0)$ & $0(0)$ \\
Positive (++) & $1(1,1)$ & $4(4)$ \\
\hline
\end{tabular}


medRxiv preprint doi: https://doi.org/10.1101/2022.02.16.22271053; this version posted February 25, 2022. The copyright holder for this preprint (which was not certified by peer review) is the author/funder, who has granted medRxiv a license to display the preprint in perpetuity.

All rights reserved. No reuse allowed without permission.

Table S7: SARS-CoV-2 PCR in environmental samples collected at nursing homes wards and reported SARS-CoV-2 infections from corresponding nursing homes

\begin{tabular}{|c|c|c|c|c|c|c|c|c|}
\hline \multirow[b]{2}{*}{ Wards } & \multicolumn{2}{|c|}{ Period 1} & \multicolumn{2}{|c|}{ Period 2} & \multicolumn{2}{|c|}{ Period 3} & \multicolumn{2}{|c|}{ Period 4} \\
\hline & $\begin{array}{c}\text { EDC - } \\
\text { Settling dust }\end{array}$ & $\begin{array}{c}\text { Infectio } \\
\text { ns }\end{array}$ & $\begin{array}{c}\text { EDC - } \\
\text { Settling dust }\end{array}$ & Infections & $\begin{array}{c}\text { EDC- } \\
\text { Settling dust }\end{array}$ & Infections & $\begin{array}{c}\text { EDC - } \\
\text { Settling dust }\end{array}$ & Infections \\
\hline $\mathrm{m}$ & $2 / 1 / 3$ & $>=3^{P}$ & $0 / 1 / 5$ & 0 & $0 / 0 / 6$ & 0 & $0 / 0 / 6$ & 0 \\
\hline $\mathrm{n}$ & $0 / 0 / 6$ & NO & $0 / 0 / 6$ & 0 & $0 / 0 / 6$ & 0 & $0 / 0 / 6$ & 0 \\
\hline o & $0 / 0 / 4$ & NO & $0 / 0 / 4$ & 0 & $0 / 0 / 4$ & 0 & $0 / 0 / 4$ & 0 \\
\hline $\mathrm{p}$ & $0 / 0 / 6$ & NO & $0 / 0 / 6$ & 0 & $0 / 0 / 6$ & 0 & $0 / 0 / 6$ & 0 \\
\hline$q^{*}$ & $0 / 1 / 1^{\text {NO }}$ & NO & $0 / 0 / 2$ & 0 & $0 / 0 / 2$ & 0 & $0 / 0 / 2$ & 0 \\
\hline$r$ & $3 / 0 / 2$ & $>=6^{P}$ & $0 / 1 / 4$ & 0 & $0 / 0 / 5$ & 0 & $0 / 0 / 5$ & 0 \\
\hline s & $0 / 0 / 5$ & $>=1^{p}$ & $0 / 0 / 5$ & $2^{P}$ & $0 / 0 / 5$ & $1^{p}$ & $0 / 0 / 5$ & 0 \\
\hline $\mathrm{t}$ & $0 / 0 / 6$ & NO & $0 / 0 / 6$ & 0 & $0 / 0 / 6$ & 0 & $0 / 0 / 6$ & 0 \\
\hline $\mathrm{u}$ & $2 / 2 / 2$ & NO**** & $0 / 0 / 6$ & 0 & $0 / 0 / 6$ & 0 & $0 / 0 / 6$ & 0 \\
\hline v & $0 / 0 / 6$ & 0 & $0 / 0 / 6$ & 0 & $0 / 0 / 6$ & 0 & $0 / 0 / 6$ & 0 \\
\hline$w$ & $0 / 0 / 5$ & 0 & $0 / 1 / 4$ & 0 & $0 / 0 / 5$ & 0 & $0 / 0 / 5$ & 0 \\
\hline$x$ & $0 / 0 / 6$ & $1^{H}$ & $0 / 0 / 6$ & $1^{H}$ & $0 / 0 / 6$ & 0 & $0 / 0 / 6$ & 0 \\
\hline$y^{* *}$ & NO & NO & NO & NO & NO & NO & NO & NO \\
\hline $\mathrm{z}^{* * *}$ & $0 / 0 / 6$ & $1^{p}$ & NO & NO & NO & NO & NO & NO \\
\hline
\end{tabular}

SARS-CoV-2 results from environmental samples: Number of positive/inconclusive/negative $/^{*}=$ two extra settling dust samples in general common areas included: restaurant and hairdresser $/^{* *}=$ no settling dust samples in common area collected $/{ }^{* * *}=$ only during outbreak measurement settling dust samples collected in common area $/ * * * *$ shortly prior to the data collection a SARS-CoV-2 outbreak occurred at the ward/ $\mathrm{P}=$ confirmed PCR SARS-CoV- 2 infection of patient $/ \mathrm{H}$ $=$ confirmed PCR SARS-CoV-2 infection of health caretaker $/>==$ not all infections were reported $/ \mathrm{NO}=$ sample/information was not obtained. 
medRxiv preprint doi: https://doi.org/10.1101/2022.02.16.22271053; this version posted February 25, 2022. The copyright holder for this preprint (which was not certified by peer review) is the author/funder, who has granted medRxiv a license to display the preprint in perpetuity.

All rights reserved. No reuse allowed without permission.

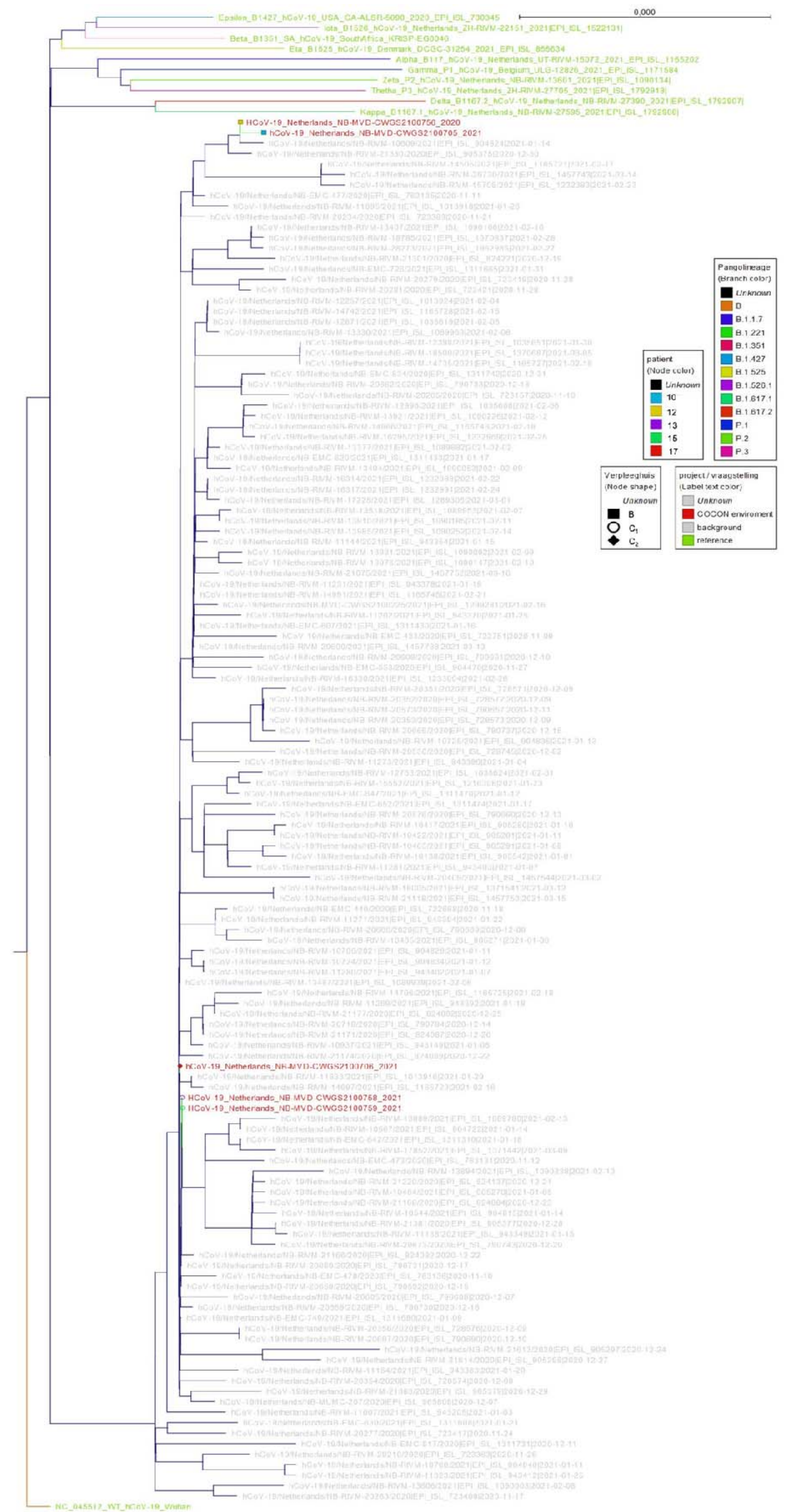

Figure S2: A phylogenetic analysis of samples with minimum $>90 \%$ reference coverage. 


\section{Table S8: Acknowledgement table Whole Genome Sequencing}

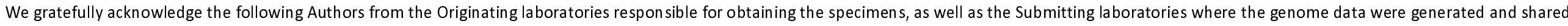
via GISAID, on which this research is based. All Submitters of data may be contacted directly via www.gisaid.org. Authors are sorted alphabetically.

\section{GISAID accession}

number

Originating lab

EPI_ISL_1165202

Dutch COVID-19 response team

EPI_ISL_736953

NHLS-IALCH

EPI_ISL_1792907

EPI_ISL_730345

Dutch COVID-19 response team San Diego County Public Health Laboratory

Department of Virus and

Microbiological Special

Diagnostics, Statens Serum

EPI_ISL_855634 Institut, Copenhagen, Denmark

EPI_ISL $1171584 \quad$ I.F.A.C. Hopital Princesse Paola

EPI_ISL_722751 Dutch COVID-19 response team

EPI_ISL_722668

Dutch COVID-19 response team

EPI_ISL_763131

Dutch COVID-19 response team

Erasmus Medical Centre

EPI_ISL_763135

Dutch COVID-19 response team

EPI_ISL_763136

Dutch COVID-19 response team

EPI_ISL 904470

Dutch COVID-19 response team

EPI_ISL_1311430
Erasmus Medical Centre

Erasmus Medical Centre

Erasmus Medical Centre

\section{Submitting lab}

ational Institute for Public

Health and the

KRISP, KZN Research

National Institute for Public

Health and the

Environment (RIVM)

Andersen lab at Scripps

Research

Aalborg University

GIGA Medical Genomics

Erasmus Medical Centre

Erasmus Medical Centre Bas Oude Munnink, Reina Sikkema, David Nieuwenhuijse, Irina Chestakova, Anne van der Linden, Marjan
Boter, Emmanuelle Munger, Corine GeurtsvanKessel, Annemiek van der Eijk, Richard Molenkamp, Marion Koopmans, on behalf of the Dutch national COVID-19 response team.

Bas Oude Munnink, Reina Sikkema, David Nieuwenhuijse, Irina Chestakova, Anne van der Linden, Marjan Boter, Emmanuelle Munger, Corine GeurtsvanKessel, Annemiek van der Eijk, Richard Molenkamp, Marion Koopmans, on behalf of the Dutch national COVID-19 response team.

Bas Oude Munnink, Reina Sikkema, David Nieuwenhuijse, Irina Chestakova, Anne van der Linden, Marjan Boter, Emmanuelle Munger, Corine GeurtsvanKessel, Annemiek van der Eijk, Richard Molenkamp, Marion Koopmans, on behalf of the Dutch national COVID-19 response team.

Bas Oude Munnink, Reina Sikkema, David Nieuwenhuijse, Irina Chestakova, Anne van der Linden, Marjan Boter, Emmanuelle Munger, Corine GeurtsvanKessel, Annemiek van der Eijk, Richard Molenkamp, Marion Koopmans, on behalf of the Dutch national COVID-19 response team.

Bas Oude Munnink, Reina Sikkema, David Nieuwenhuijse, Irina Chestakova, Anne van der Linden, Marjan Boter, Emmanuelle Munger, Corine GeurtsvanKessel, Annemiek van der Eijk, Richard Molenkamp, Marion Koopmans, on behalf of the Dutch national COVID-19 response team.

Bas Oude Munnink, Reina Sikkema, David Nieuwenhuijse, Irina Chestakova, Anne van der Linden, Marjan Boter, Emmanuelle Munger, Corine GeurtsvanKessel, Annemiek van der Eijk, Richard Molenkamp, Marion Koopmans, on behalf of the Dutch national COVID-19 response team.
Innovation and Sequencing 
EPI_ISL_1311433

Dutch COVID-19 response team

EPI_ISL_1311608

Dutch COVID-19 response team

EPI_ISL_1311310

Dutch COVID-19 response team

EPI_ISL_1311470

Dutch COVID-19 response team

EPI_ISL_1311474

Dutch COVID-19 response team

EPI_ISL_1311665

Dutch COVID-19 response team

EPI_ISL_1311680

Dutch COVID-19 response team

EPI_ISL_1311731 Dutch COVID-19 response team

EPI_ISL_1311742

Dutch COVID-19 response team

EPI_ISL_965808

Dutch COVID-19 response team

EPI ISL 1299281

EPI_ISL_905542 Dutch COVID-19 response team

EPI_ISL_905270 Dutch COVID-19 response team

EPI_ISL_905271 Dutch COVID-19 response team

EPI_ISL_905280 Dutch COVID-19 response team

EPI_ISL_905281 Dutch COVID-19 response team

EPI_ISL_905291
Erasmus Medical Centre

Erasmus Medical Centre

Erasmus Medical Centre

Erasmus Medical Centre

Erasmus Medical Centre

Erasmus Medical Centre

Erasmus Medical Centre

Erasmus Medical Centre

Erasmus Medical Centre Medical Microbiology, Maastricht University

Medical Centre

Microvida

National Institute for Public Health and the

Environment (RIVM)

National Institute for Public

Health and the

Environment (RIVM)

National Institute for Public

Health and the

Environment (RIVM)

National Institute for Public

Health and the

Environment (RIVM)

National Institute for Public

Health and the

Environment (RIVM)

Environment (RIVM)

Neational Institu and the

Environment (RIVM)
Bas Oude Munnink, Reina Sikkema, David Nieuwenhuijse, Irina Chestakova, Anne van der Linden, Marjan Boter, Emmanuelle Munger, Corine GeurtsvanKessel, Annemiek van der Eijk, Richard Molenkamp, Marion Koopmans, on behalf of the Dutch national COVID-19 response team.

Bas Oude Munnink, Reina Sikkema, David Nieuwenhuijse, Irina Chestakova, Anne van der Linden, Marjan Boter, Emmanuelle Munger, Corine GeurtsvanKessel, Annemiek van der Eijk, Richard Molenkamp, Marion Koopmans, on behalf of the Dutch national COVID-19 response team.

Bas Oude Munnink, Reina Sikkema, David Nieuwenhuijse, Irina Chestakova, Anne van der Linden, Marjan Boter, Emmanuelle Munger, Corine GeurtsvanKessel, Annemiek van der Eijk, Richard Molenkamp, Marion Koopmans, on behalf of the Dutch national COVID-19 response team.

Bas Oude Munnink, Reina Sikkema, David Nieuwenhuijse, Irina Chestakova, Anne van der Linden, Marjan Boter, Emmanuelle Munger, Corine GeurtsvanKessel, Annemiek van der Eijk, Richard Molenkamp, Marion Koopmans, on behalf of the Dutch national COVID-19 response team.

Bas Oude Munnink, Reina Sikkema, David Nieuwenhuijse, Irina Chestakova, Anne van der Linden, Marjan Boter, Emmanuelle Munger, Corine GeurtsvanKessel, Annemiek van der Eijk, Richard Molenkamp, Marion Koopmans, on behalf of the Dutch national COVID-19 response team.

Bas Oude Munnink, Reina Sikkema, David Nieuwenhuijse, Irina Chestakova, Anne van der Linden, Marjan Boter, Emmanuelle Munger, Corine GeurtsvanKessel, Annemiek van der Eijk, Richard Molenkamp, Marion Koopmans, on behalf of the Dutch national COVID-19 response team.

Bas Oude Munnink, Reina Sikkema, David Nieuwenhuijse, Irina Chestakova, Anne van der Linden, Marjan Boter, Emmanuelle Munger, Corine GeurtsvanKessel, Annemiek van der Eijk, Richard Molenkamp, Marion Koopmans, on behalf of the Dutch national COVID-19 response team.

Bas Oude Munnink, Reina Sikkema, David Nieuwenhuijse, Irina Chestakova, Anne van der Linden, Marjan Boter, Emmanuelle Munger, Corine GeurtsvanKessel, Annemiek van der Eijk, Richard Molenkamp, Marion Koopmans, on behalf of the Dutch national COVID-19 response team.

Bas Oude Munnink, Reina Sikkema, David Nieuwenhuijse, Irina Chestakova, Anne van der Linden, Marjan Boter, Emmanuelle Munger, Corine GeurtsvanKessel, Annemiek van der Eijk, Richard Molenkamp, Marion Koopmans, on behalf of the Dutch national COVID-19 response team.

Jozef Dingemans*, Brian van der Veer*, Erik Beuken, Carmen Reumkens, Lieke van Alphen, Christian Hoebe, Paul Savelkoul

S.D. Pas, J.J. Verweij, J. Stohr

Adam Meijer, Harry Vennema, Dirk Eggink, Jeroen Cremer, Sharon van den Brink, Bas van der Veer, AnneMarie van den Brandt, Florian Zwagemaker, Dennis Schmitz, Chantal Reusken, on behalf of the national COVID-19 response team

Adam Meijer, Harry Vennema, Dirk Eggink, Jeroen Cremer, Sharon van den Brink, Bas van der Veer, AnneMarie van den Brandt, Florian Zwagemaker, Dennis Schmitz, Chantal Reusken, on behalf of the national COVID-19 response team

Adam Meijer, Harry Vennema, Dirk Eggink, Jeroen Cremer, Sharon van den Brink, Bas van der Veer, AnneMarie van den Brandt, Florian Zwagemaker, Dennis Schmitz, Chantal Reusken, on behalf of the national COVID-19 response team

Adam Meijer, Harry Vennema, Dirk Eggink, Jeroen Cremer, Sharon van den Brink, Bas van der Veer, AnneMarie van den Brandt, Florian Zwagemaker, Dennis Schmitz, Chantal Reusken, on behalf of the national COVID-19 response team

Adam Meijer, Harry Vennema, Dirk Eggink, Jeroen Cremer, Sharon van den Brink, Bas van der Veer, AnneMarie van den Brandt, Florian Zwagemaker, Dennis Schmitz, Chantal Reusken, on behalf of the

national COVID-19 response team Adam Meijer, Harry Vennema, Dirk Eggink, Jeroen Cremer, Sharon van den Brink, Bas van der Veer,
AnneMarie van den Brandt, Florian Zwagemaker, Dennis Schmitz, Chantal Reusken, on behalf of the national COVID-19 response team 
EPI ISL_904815

Dutch COVID-19 response team

EPI_ISL_904722

Dutch COVID-19 response team

EPI_ISL_904824

Dutch COVID-19 response team

EPI_ISL_904826

Dutch COVID-19 response team

Dutch COVID-19 response team

EPI_ISL 904835

Dutch COVID-19 response team

EPI ISL_904840

Dutch COVID-19 response team

EPI_ISL_943149

Dutch COVID-19 response team

EPI_ISL_943205

Dutch COVID-19 response team

EPI_ISL 943349

Dutch COVID-19 response team

EPI_ISL 943354

EPI_ISL_943363

EPI_ISL_943370

EPI_ISL_943378

EPI_ISL_943392

EPI ISL 943394

EPI_ISL_943396

EPI_ISL_943402

Dutch COVID-19 response team

EPI_ISL_943403
National Institute for Public Health and the

Environment (RIVM)

National Institute for Public

Health and the

Environment (RIVM)

National Institute for Public

Health and the

Environment (RIVM)

National Institute for Public

Health and the

Environment (RIVM)

National Institute for Public

Health and the

Environment (RIVM)

National Institute for Public

Health and the

Environment (RIVM)

National Institute for Public

Health and the

Environment (RIVM)

National Institute for Public

Health and the

Environment (RIVM)

National Institute for Public

Health and the

Environment (RIVM)

National Institute for Public

Health and the

Environment (RIVM)

National Institute for Public

Health and the

Environment (RIVM)

National Institute for Public

Health and the

Environment (RIVM)

National Institute for Public

Health and the

Environment (RIVM)

National Institute for Public

Health and the

Environment (RIVM)

National Institute for Public

Health and the

National Institute for Public

Health and the

Environment (RIVM)

National Institute for Public

Health and the

Environment (RIVM)

National Institute for Public

Health and the

Environment (RIVM)

National Institute for Public

Health and the

Environment (RIVM)
Adam Meijer, Harry Vennema, Dirk Eggink, Jeroen Cremer, Sharon van den Brink, Bas van der Veer, AnneMarie van den Brandt, Florian Zwagemaker, Dennis Schmitz, Chantal Reusken, on behalf of the national COVID-19 response team

Adam Meijer, Harry Vennema, Dirk Eggink, Jeroen Cremer, Sharon van den Brink, Bas van der Veer, AnneMarie van den Brandt, Florian Zwagemaker, Dennis Schmitz, Chantal Reusken, on behalf of the AnneMarie van den Brandt, Florian $Z$

national COVID-19 response team AnneMarie van den Brandt, Florian Zwagemaker, Dennis Schmitz, Chantal Reusken, on behalf of the national COVID-19 response team

Adam Meijer, Harry Vennema, Dirk Eggink, Jeroen Cremer, Sharon van den Brink, Bas van der Veer, AnneMarie van den Brandt, Florian Zwagemaker, Dennis Schmitz, Chantal Reusken, on behalf of the national COVID-19 response team

Adam Meijer, Harry Vennema, Dirk Eggink, Jeroen Cremer, Sharon van den Brink, Bas van der Veer, AnneMarie van den Brandt, Florian Zwagemaker, Dennis Schmitz, Chantal Reusken, on behalf of the national COVID-19 response team

Adam Meijer, Harry Vennema, Dirk Eggink, Jeroen Cremer, Sharon van den Brink, Bas van der Veer, AnneMarie van den Brandt, Florian Zwagemaker, Dennis Schmitz, Chantal Reusken, on behalf of the national COVID-19 response team

Adam Meijer, Harry Vennema, Dirk Eggink, Jeroen Cremer, Sharon van den Brink, Bas van der Veer, AnneMarie van den Brandt, Florian Zwagemaker, Dennis Schmitz, Chantal Reusken, on behalf of the national COVID-19 response team

Adam Meijer, Harry Vennema, Dirk Eggink, Jeroen Cremer, Sharon van den Brink, Bas van der Veer, AnneMarie van den Brandt, Florian Zwagemaker, Dennis Schmitz, Chantal Reusken, on behalf of the national COVID-19 response team

Adam Meijer, Harry Vennema, Dirk Eggink, Jeroen Cremer, Sharon van den Brink, Bas van der Veer, AnneMarie van den Brandt, Florian Zwagemaker, Dennis Schmitz, Chantal Reusken, on behalf of the national COVID-19 response team

Adam Meijer, Harry Vennema, Dirk Eggink, Jeroen Cremer, Sharon van den Brink, Bas van der Veer, AnneMarie van den Brandt, Florian Zwagemaker, Dennis Schmitz, Chantal Reusken, on behalf of the national COVID-19 response team

Adam Meijer, Harry Vennema, Dirk Eggink, Jeroen Cremer, Sharon van den Brink, Bas van der Veer, AnneMarie van den Brandt, Florian Zwagemaker, Dennis Schmitz, Chantal Reusken, on behalf of the national COVID-19 response team

Adam Meijer, Harry Vennema, Dirk Eggink, Jeroen Cremer, Sharon van den Brink, Bas van der Veer, AnneMarie van den Brandt, Florian Zwagemaker, Dennis Schmitz, Chantal Reusken, on behalf of the national COVID-19 response team

Adam Meijer, Harry Vennema, Dirk Eggink, Jeroen Cremer, Sharon van den Brink, Bas van der Veer, AnneMarie van den Brandt, Florian Zwagemaker, Dennis Schmitz, Chantal Reusken, on behalf of the national COVID-19 response team

Adam Meijer, Harry Vennema, Dirk Eggink, Jeroen Cremer, Sharon van den Brink, Bas van der Veer, AnneMarie van den Brandt, Florian Zwagemaker, Dennis Schmitz, Chantal Reusken, on behalf of the national COVID-19 response team

Adam Meijer, Harry Vennema, Dirk Eggink, Jeroen Cremer, Sharon van den Brink, Bas van der Veer, AnneMarie van den Brandt, Florian Zwagemaker, Dennis Schmitz, Chantal Reusken, on behalf of the national COVID-19 response team

Adam Meijer, Harry Vennema, Dirk Eggink, Jeroen Cremer, Sharon van den Brink, Bas van der Veer, AnneMarie van den Brandt, Florian Zwagemaker, Dennis Schmitz, Chantal Reusken, on behalf of the national COVID-19 response team

Adam Meijer, Harry Vennema, Dirk Eggink, Jeroen Cremer, Sharon van den Brink, Bas van der Veer, AnneMarie van den Brandt, Florian Zwagemaker, Dennis Schmitz, Chantal Reusken, on behalf of the national COVID-19 response team

Adam Meijer, Harry Vennema, Dirk Eggink, Jeroen Cremer, Sharon van den Brink, Bas van der Veer, AnneMarie van den Brandt, Florian Zwagemaker, Dennis Schmitz, Chantal Reusken, on behalf of the national COVID-19 response team

Adam Meijer, Harry Vennema, Dirk Eggink, Jeroen Cremer, Sharon van den Brink, Bas van der Veer, AnneMarie van den Brandt, Florian Zwagemaker, Dennis Schmitz, Chantal Reusken, on behalf of the national COVID-19 response team 
EPI_ISL_943412

Dutch COVID-19 response team

EPI_ISL_1013916

Dutch COVID-19 response team

EPI_ISL_1013918

Dutch COVID-19 response team

EPI_ISL_1013924

Dutch COVID-19 response team

EPI_ISL_1035651

Dutch COVID-19 response team

EPI_ISL_1035624 Dutch COVID-19 response team

EPI_ISL_1035619 Dutch COVID-19 response team

EPI_ISL_1035608 Dutch COVID-19 response team

EPI_ISL_1089963 Dutch COVID-19 response team

EPI_ISL_1089882 Dutch COVID-19 response team

EPI_ISL_1090053 Dutch COVID-19 response team

EPI_ISL_1090106 Dutch COVID-19 response team

EPI_ISL_1089939 Dutch COVID-19 response team

EPI_ISL_1089953 Dutch COVID-19 response team

EPI_ISL_1090003 Dutch COVID-19 response team

EPI_ISL_1089780 Dutch COVID-19 response team

EPI_ISL_1090238 Dutch COVID-19 response team

EPI_ISL_1090185 Dutch COVID-19 response team

EPI ISL_1090226 Dutch COVID-19 response team
National Institute for Public Health and the

Environment (RIVM)

National Institute for Public

Health and the

Environment (RIVM)

National Institute for Public

Health and the

Environment (RIVM)

National Institute for Public

Health and the

Environment (RIVM)

National Institute for Public

Health and the

Environment (RIVM)

National Institute for Public

Health and the

Environment (RIVM)

National Institute for Public

Health and the

Environment (RIVM)

National Institute for Public

National Institute
Health and the

Health and the
Environment (RIVM)

National Institute for Public

Health and the

Environment (RIVM)

National Institute for Public

Health and the

Environment (RIVM)

National Institute for Public

Health and the

Environment (RIVM)

National Institute for Public

Health and the

Environment (RIVM)

National Institute for Public

Health and the

Environment (RIVM)

National Institute for Public

Health and the

Environment (RIVM)

National Institute for Public

Health and the

Environment (RIVM)

National Institute for Public

Health and the

Environment (RIVM)

National Institute for Public

Neational Institu and the

Health and the
Environment (RIVM)

Environment (RIVM)

Health and the

Environment (RIVM)

National Institute for Public

Health and the

Environment (RIVM)
Adam Meijer, Harry Vennema, Dirk Eggink, Jeroen Cremer, Sharon van den Brink, Bas van der Veer, AnneMarie van den Brandt, Florian Zwagemaker, Dennis Schmitz, Chantal Reusken, on behalf of the national COVID-19 response team

Adam Meijer, Harry Vennema, Dirk Eggink, Jeroen Cremer, Sharon van den Brink, Bas van der Veer, AnneMarie van den Brandt, Florian Zwagemaker, Dennis Schmitz, Chantal Reusken, on behalf of the AnneMarie van den Brandt, Florian $Z$

Adam Meijer, Harry Vennema, Dirk Eggink, Jeroen Cremer, Sharon van den Brink, Bas van der Veer, AnneMarie van den Brandt, Florian Zwagemaker, Dennis Schmitz, Chantal Reusken, on behalf of the national COVID-19 response team

Adam Meijer, Harry Vennema, Dirk Eggink, Jeroen Cremer, Sharon van den Brink, Bas van der Veer, AnneMarie van den Brandt, Florian Zwagemaker, Dennis Schmitz, Chantal Reusken, on behalf of the national COVID-19 response team

Adam Meijer, Harry Vennema, Dirk Eggink, Jeroen Cremer, Sharon van den Brink, Bas van der Veer, AnneMarie van den Brandt, Florian Zwagemaker, Dennis Schmitz, Chantal Reusken, on behalf of the national COVID-19 response team

Adam Meijer, Harry Vennema, Dirk Eggink, Jeroen Cremer, Sharon van den Brink, Bas van der Veer, AnneMarie van den Brandt, Florian Zwagemaker, Dennis Schmitz, Chantal Reusken, on behalf of the national COVID-19 response team

Adam Meijer, Harry Vennema, Dirk Eggink, Jeroen Cremer, Sharon van den Brink, Bas van der Veer, AnneMarie van den Brandt, Florian Zwagemaker, Dennis Schmitz, Chantal Reusken, on behalf of the national COVID-19 response team

Adam Meijer, Harry Vennema, Dirk Eggink, Jeroen Cremer, Sharon van den Brink, Bas van der Veer, AnneMarie van den Brandt, Florian Zwagemaker, Dennis Schmitz, Chantal Reusken, on behalf of the national COVID-19 response team

Adam Meijer, Harry Vennema, Dirk Eggink, Jeroen Cremer, Sharon van den Brink, Bas van der Veer, AnneMarie van den Brandt, Florian Zwagemaker, Dennis Schmitz, Chantal Reusken, on behalf of the national COVID-19 response team

Adam Meijer, Harry Vennema, Dirk Eggink, Jeroen Cremer, Sharon van den Brink, Bas van der Veer, AnneMarie van den Brandt, Florian Zwagemaker, Dennis Schmitz, Chantal Reusken, on behalf of the national COVID-19 response team

Adam Meijer, Harry Vennema, Dirk Eggink, Jeroen Cremer, Sharon van den Brink, Bas van der Veer, AnneMarie van den Brandt, Florian Zwagemaker, Dennis Schmitz, Chantal Reusken, on behalf of the national COVID-19 response team

Adam Meijer, Harry Vennema, Dirk Eggink, Jeroen Cremer, Sharon van den Brink, Bas van der Veer, AnneMarie van den Brandt, Florian Zwagemaker, Dennis Schmitz, Chantal Reusken, on behalf of the national COVID-19 response team

Adam Meijer, Harry Vennema, Dirk Eggink, Jeroen Cremer, Sharon van den Brink, Bas van der Veer, AnneMarie van den Brandt, Florian Zwagemaker, Dennis Schmitz, Chantal Reusken, on behalf of the national COVID-19 response team

Adam Meijer, Harry Vennema, Dirk Eggink, Jeroen Cremer, Sharon van den Brink, Bas van der Veer, AnneMarie van den Brandt, Florian Zwagemaker, Dennis Schmitz, Chantal Reusken, on behalf of the national COVID-19 response team

Adam Meijer, Harry Vennema, Dirk Eggink, Jeroen Cremer, Sharon van den Brink, Bas van der Veer, AnneMarie van den Brandt, Florian Zwagemaker, Dennis Schmitz, Chantal Reusken, on behalf of the national COVID-19 response team

Adam Meijer, Harry Vennema, Dirk Eggink, Jeroen Cremer, Sharon van den Brink, Bas van der Veer, AnneMarie van den Brandt, Florian Zwagemaker, Dennis Schmitz, Chantal Reusken, on behalf of the national COVID-19 response team

Adam Meijer, Harry Vennema, Dirk Eggink, Jeroen Cremer, Sharon van den Brink, Bas van der Veer, AnneMarie van den Brandt, Florian Zwagemaker, Dennis Schmitz, Chantal Reusken, on behalf of the national COVID-19 response team

Adam Meijer, Harry Vennema, Dirk Eggink, Jeroen Cremer, Sharon van den Brink, Bas van der Veer, AnneMarie van den Brandt, Florian Zwagemaker, Dennis Schmitz, Chantal Reusken, on behalf of the national COVID-19 response team

Adam Meijer, Harry Vennema, Dirk Eggink, Jeroen Cremer, Sharon van den Brink, Bas van der Veer, AnneMarie van den Brandt, Florian Zwagemaker, Dennis Schmitz, Chantal Reusken, on behalf of the national COVID-19 response team 
EPI_ISL_1090092 Dutch COVID-19 response team

EPI_ISL_1090147 Dutch COVID-19 response team

EPI_ISL_1090252 Dutch COVID-19 response team

EPI_ISL_1165721 Dutch COVID-19 response team

EPI_ISL_1165723 Dutch COVID-19 response team

EPI_ISL_1165725 Dutch COVID-19 response team

EPI_ISL_1165727 Dutch COVID-19 response team

EPI_ISL_1165728 Dutch COVID-19 response team

EPI_ISL_1165743 Dutch COVID-19 response team

EPI ISL 1165745 Dutch COVID-19 response team

EPI ISL 1216308 Dutch COVID-19 response team

EPI_ISL_1232383 Dutch COVID-19 response team

EPI_ISL_1232969 Dutch COVID-19 response team

EPI_ISL_1232988 Dutch COVID-19 response team

EPI_ISL_1232991 Dutch COVID-19 response team

EPI ISL_1233004 Dutch COVID-19 response team

EPI_ISL_1289305 Dutch COVID-19 response team

EPI_ISL_1371442 Dutch COVID-19 response team

EPI_ISL_1371541 Dutch COVID-19 response team
National Institute for Public Health and the

Environment (RIVM)

National Institute for Public

Health and the

Environment (RIVM)

National Institute for Public

Health and the

Environment (RIVM)

National Institute for Public

Health and the

Environment (RIVM)

National Institute for Public

Health and the

Environment (RIVM)

National Institute for Public

Health and the

Environment (RIVM)

National Institute for Public

Health and the

Environment (RIVM)

National Institute for Public

Health and the

Environment (RIVM)

National Institute for Public

Health and the

Environment (RIVM)

National Institute for Public

Health and the

National Institute for Public

Health and the

Environment (RIVM)

National Institute for Public

Health and the

Environment (RIVM)

National Institute for Public

Health and the

Environment (RIVM)

National Institute for Public

Health and the

Environment (RIVM)

National Institute for Public

Health and the

Environment (RIVM)

National Institute for Public

Health and the

Environment (RIVM)

National Institute for Public

Health and the

Environment (RIVM)

National Institute for Public

Health and the

Environment (RIVM)

National Institute for Public

Health and the

Environment (RIVM)
Adam Meijer, Harry Vennema, Dirk Eggink, Jeroen Cremer, Sharon van den Brink, Bas van der Veer, AnneMarie van den Brandt, Florian Zwagemaker, Dennis Schmitz, Chantal Reusken, on behalf of the national COVID-19 response team

Adam Meijer, Harry Vennema, Dirk Eggink, Jeroen Cremer, Sharon van den Brink, Bas van der Veer, AnneMarie van den Brandt, Florian Zwagemaker, Dennis Schmitz, Chantal Reusken, on behalf of the AnneMarie van den Brandt, Florian $Z$

Adam Meijer, Harry Vennema, Dirk Eggink, Jeroen Cremer, Sharon van den Brink, Bas van der Veer, AnneMarie van den Brandt, Florian Zwagemaker, Dennis Schmitz, Chantal Reusken, on behalf of the national COVID-19 response team

Adam Meijer, Harry Vennema, Dirk Eggink, Jeroen Cremer, Sharon van den Brink, Bas van der Veer, AnneMarie van den Brandt, Florian Zwagemaker, Dennis Schmitz, Chantal Reusken, on behalf of the national COVID-19 response team

Adam Meijer, Harry Vennema, Dirk Eggink, Jeroen Cremer, Sharon van den Brink, Bas van der Veer, AnneMarie van den Brandt, Florian Zwagemaker, Dennis Schmitz, Chantal Reusken, on behalf of the national COVID-19 response team

Adam Meijer, Harry Vennema, Dirk Eggink, Jeroen Cremer, Sharon van den Brink, Bas van der Veer, AnneMarie van den Brandt, Florian Zwagemaker, Dennis Schmitz, Chantal Reusken, on behalf of the national COVID-19 response team

Adam Meijer, Harry Vennema, Dirk Eggink, Jeroen Cremer, Sharon van den Brink, Bas van der Veer, AnneMarie van den Brandt, Florian Zwagemaker, Dennis Schmitz, Chantal Reusken, on behalf of the national COVID-19 response team

Adam Meijer, Harry Vennema, Dirk Eggink, Jeroen Cremer, Sharon van den Brink, Bas van der Veer, AnneMarie van den Brandt, Florian Zwagemaker, Dennis Schmitz, Chantal Reusken, on behalf of the national COVID-19 response team

Adam Meijer, Harry Vennema, Dirk Eggink, Jeroen Cremer, Sharon van den Brink, Bas van der Veer, AnneMarie van den Brandt, Florian Zwagemaker, Dennis Schmitz, Chantal Reusken, on behalf of the national COVID-19 response team

Adam Meijer, Harry Vennema, Dirk Eggink, Jeroen Cremer, Sharon van den Brink, Bas van der Veer, AnneMarie van den Brandt, Florian Zwagemaker, Dennis Schmitz, Chantal Reusken, on behalf of the national COVID-19 response team

Adam Meijer, Harry Vennema, Dirk Eggink, Jeroen Cremer, Sharon van den Brink, Bas van der Veer, AnneMarie van den Brandt, Florian Zwagemaker, Dennis Schmitz, Chantal Reusken, on behalf of the national COVID-19 response team

Adam Meijer, Harry Vennema, Dirk Eggink, Jeroen Cremer, Sharon van den Brink, Bas van der Veer, AnneMarie van den Brandt, Florian Zwagemaker, Dennis Schmitz, Chantal Reusken, on behalf of the national COVID-19 response team

Adam Meijer, Harry Vennema, Dirk Eggink, Jeroen Cremer, Sharon van den Brink, Bas van der Veer, AnneMarie van den Brandt, Florian Zwagemaker, Dennis Schmitz, Chantal Reusken, on behalf of the national COVID-19 response team

Adam Meijer, Harry Vennema, Dirk Eggink, Jeroen Cremer, Sharon van den Brink, Bas van der Veer, AnneMarie van den Brandt, Florian Zwagemaker, Dennis Schmitz, Chantal Reusken, on behalf of the national COVID-19 response team

Adam Meijer, Harry Vennema, Dirk Eggink, Jeroen Cremer, Sharon van den Brink, Bas van der Veer, AnneMarie van den Brandt, Florian Zwagemaker, Dennis Schmitz, Chantal Reusken, on behalf of the national COVID-19 response team

Adam Meijer, Harry Vennema, Dirk Eggink, Jeroen Cremer, Sharon van den Brink, Bas van der Veer, AnneMarie van den Brandt, Florian Zwagemaker, Dennis Schmitz, Chantal Reusken, on behalf of the national COVID-19 response team

Adam Meijer, Harry Vennema, Dirk Eggink, Jeroen Cremer, Sharon van den Brink, Bas van der Veer, AnneMarie van den Brandt, Florian Zwagemaker, Dennis Schmitz, Chantal Reusken, on behalf of the national COVID-19 response team

Adam Meijer, Harry Vennema, Dirk Eggink, Jeroen Cremer, Sharon van den Brink, Bas van der Veer, AnneMarie van den Brandt, Florian Zwagemaker, Dennis Schmitz, Chantal Reusken, on behalf of the national COVID-19 response team

Adam Meijer, Harry Vennema, Dirk Eggink, Jeroen Cremer, Sharon van den Brink, Bas van der Veer, AnneMarie van den Brandt, Florian Zwagemaker, Dennis Schmitz, Chantal Reusken, on behalf of the national COVID-19 response team 
National Institute for Public Health and the

EPI_ISL_1370687 Dutch COVID-19 response team

EPI ISL 1370837 Dutch COVID-19 response team

Dutch COVID-19 response team

EPI_ISL_723383 Dutch COVID-19 response team

EPI_ISL_723409 Dutch COVID-19 response team

EPI_ISL_723157 Dutch COVID-19 response team

EPI_ISL_723417 Dutch COVID-19 response team

EPI_ISL_723419 Dutch COVID-19 response team

EPI_ISL_723421 Dutch COVID-19 response team

EPI ISL 728571 Dutch COVID-19 response team

EPI ISL 728572 Dutch COVID-19 response team

EPI_ISL_728573 Dutch COVID-19 response team

EPI_ISL_728574 Dutch COVID-19 response team

EPI_ISL_728576 Dutch COVID-19 response team

EPI ISL 1457544 Dutch COVID-19 response team

EPI ISL 728745 Dutch COVID-19 response team

EPI_ISL_790657 Dutch COVID-19 response team

EPI_ISL_790660 Dutch COVID-19 response team

EPI_ISL_1457738
Environment (RIVM)

National Institute for Public

Health and the

Environment (RIVM)

National Institute for Public

Health and the

Environment (RIVM)

National Institute for Public

Health and the

Environment (RIVM)

National Institute for Public

Health and the

Environment (RIVM)

National Institute for Public

Health and the

Environment (RIVM)

National Institute for Public

Health and the

Environment (RIVM)

National Institute for Public

Health and the

Environment (RIVM)

National Institute for Public

Health and the

Environment (RIVM)

National Institute for Public

Health and the

National Institute for Public

Health and the

Environment (RIVM)

National Institute for Public

Health and the

Environment (RIVM)

National Institute for Public

Health and the

Environment (RIVM)

National Institute for Public

Health and the

Environment (RIVM)

National Institute for Public

Health and the

Environment (RIVM)

National Institute for Public

Health and the

Environment (RIVM)

National Institute for Public

Health and the

Environment (RIVM)

National Institute for Public

Health and the

Environment (RIVM)

National Institute for Public

Health and the

Environment (RIVM)
Adam Meijer, Harry Vennema, Dirk Eggink, Jeroen Cremer, Sharon van den Brink, Bas van der Veer, AnneMarie van den Brandt, Florian Zwagemaker, Dennis Schmitz, Chantal Reusken, on behalf of the national COVID-19 response team

Adam Meijer, Harry Vennema, Dirk Eggink, Jeroen Cremer, Sharon van den Brink, Bas van der Veer, AnneMarie van den Brandt, Florian Zwagemaker, Dennis Schmitz, Chantal Reusken, on behalf of the AnneMarie van den Brandt, Florian

Adam Meijer, Harry Vennema, Dirk Eggink, Jeroen Cremer, Sharon van den Brink, Bas van der Veer, AnneMarie van den Brandt, Florian Zwagemaker, Dennis Schmitz, Chantal Reusken, on behalf of the national COVID-19 response team

Adam Meijer, Harry Vennema, Dirk Eggink, Jeroen Cremer, Sharon van den Brink, Bas van der Veer, AnneMarie van den Brandt, Florian Zwagemaker, Dennis Schmitz, Chantal Reusken, on behalf of the national COVID-19 response team

Adam Meijer, Harry Vennema, Dirk Eggink, Jeroen Cremer, Sharon van den Brink, Bas van der Veer, AnneMarie van den Brandt, Florian Zwagemaker, Dennis Schmitz, Chantal Reusken, on behalf of the national COVID-19 response team

Adam Meijer, Harry Vennema, Dirk Eggink, Jeroen Cremer, Sharon van den Brink, Bas van der Veer, AnneMarie van den Brandt, Florian Zwagemaker, Dennis Schmitz, Chantal Reusken, on behalf of the national COVID-19 response team

Adam Meijer, Harry Vennema, Dirk Eggink, Jeroen Cremer, Sharon van den Brink, Bas van der Veer, AnneMarie van den Brandt, Florian Zwagemaker, Dennis Schmitz, Chantal Reusken, on behalf of the national COVID-19 response team

Adam Meijer, Harry Vennema, Dirk Eggink, Jeroen Cremer, Sharon van den Brink, Bas van der Veer, AnneMarie van den Brandt, Florian Zwagemaker, Dennis Schmitz, Chantal Reusken, on behalf of the national COVID-19 response team

Adam Meijer, Harry Vennema, Dirk Eggink, Jeroen Cremer, Sharon van den Brink, Bas van der Veer, AnneMarie van den Brandt, Florian Zwagemaker, Dennis Schmitz, Chantal Reusken, on behalf of the national COVID-19 response team

Adam Meijer, Harry Vennema, Dirk Eggink, Jeroen Cremer, Sharon van den Brink, Bas van der Veer, AnneMarie van den Brandt, Florian Zwagemaker, Dennis Schmitz, Chantal Reusken, on behalf of the national COVID-19 response team

Adam Meijer, Harry Vennema, Dirk Eggink, Jeroen Cremer, Sharon van den Brink, Bas van der Veer, AnneMarie van den Brandt, Florian Zwagemaker, Dennis Schmitz, Chantal Reusken, on behalf of the national COVID-19 response team

Adam Meijer, Harry Vennema, Dirk Eggink, Jeroen Cremer, Sharon van den Brink, Bas van der Veer, AnneMarie van den Brandt, Florian Zwagemaker, Dennis Schmitz, Chantal Reusken, on behalf of the national COVID-19 response team

Adam Meijer, Harry Vennema, Dirk Eggink, Jeroen Cremer, Sharon van den Brink, Bas van der Veer, AnneMarie van den Brandt, Florian Zwagemaker, Dennis Schmitz, Chantal Reusken, on behalf of the national COVID-19 response team

Adam Meijer, Harry Vennema, Dirk Eggink, Jeroen Cremer, Sharon van den Brink, Bas van der Veer, AnneMarie van den Brandt, Florian Zwagemaker, Dennis Schmitz, Chantal Reusken, on behalf of the national COVID-19 response team

Adam Meijer, Harry Vennema, Dirk Eggink, Jeroen Cremer, Sharon van den Brink, Bas van der Veer, AnneMarie van den Brandt, Florian Zwagemaker, Dennis Schmitz, Chantal Reusken, on behalf of the national COVID-19 response team

Adam Meijer, Harry Vennema, Dirk Eggink, Jeroen Cremer, Sharon van den Brink, Bas van der Veer, AnneMarie van den Brandt, Florian Zwagemaker, Dennis Schmitz, Chantal Reusken, on behalf of the national COVID-19 response team

Adam Meijer, Harry Vennema, Dirk Eggink, Jeroen Cremer, Sharon van den Brink, Bas van der Veer, AnneMarie van den Brandt, Florian Zwagemaker, Dennis Schmitz, Chantal Reusken, on behalf of the national COVID-19 response team

Adam Meijer, Harry Vennema, Dirk Eggink, Jeroen Cremer, Sharon van den Brink, Bas van der Veer, AnneMarie van den Brandt, Florian Zwagemaker, Dennis Schmitz, Chantal Reusken, on behalf of the national COVID-19 response team

Adam Meijer, Harry Vennema, Dirk Eggink, Jeroen Cremer, Sharon van den Brink, Bas van der Veer, AnneMarie van den Brandt, Florian Zwagemaker, Dennis Schmitz, Chantal Reusken, on behalf of the national COVID-19 response team 
EPI_ISL_790688

Dutch COVID-19 response team

EPI_ISL_790689

Dutch COVID-19 response team

EPI_ISL_790690

Dutch COVID-19 response team

EPI_ISL_790691

Dutch COVID-19 response team

EPI_ISL_790592

Dutch COVID-19 response team

EPI_ISL_790730

Dutch COVID-19 response team

EPI_ISL_790731

EPI_ISL_790733

EPI_ISL_790737

EPI_ISL_790743

EPI_ISL_790784

EPI_ISL_1457743

EPI_ISL_1457752

EPI_ISL_1457753

EPI_ISL_824082

Dutch COVID-19 response team

EPI ISL 824084

EPI_ISL_824087

EPI_ISL_824089

Dutch COVID-19 response team

EPI_ISL_824092
Health and the

Environment (RIVM)

National Institute for Public

Health and the

Environment (RIVM)

National Institute for Public

Health and the

Environment (RIVM)

National Institute for Public

Health and the

Environment (RIVM)

National Institute for Public

Health and the

Environment (RIVM)

National Institute for Public

Health and the

Environment (RIVM)

National Institute for Public

Health and the

Environment (RIVM)

National Institute for Public

Health and the

Environment (RIVM)

National Institute for Public

Health and the

Environment (RIVM)

National Institute for Public

Health and the

Environment (RIVM)

National Institute for Public

Health and the

Environment (RIVM)

National Institute for Public

Health and the

Environment (RIVM)

National Institute for Public

Health and the

Environment (RIVM)

National Institute for Public

Health and the

Environment (RIVM)

National Institute for Public

Health and the

Environment (RIVM)

National Institute for Public

Health and the

Environment (RIVM)

National Institute for Public

Nealth and the

Health and the
Environment (RIVM)

Environment (RIVM)
National Institute for Public

Health and the

Environment (RIVM)

National Institute for Public

Health and the

Environment (RIVM)
Adam Meijer, Harry Vennema, Dirk Eggink, Jeroen Cremer, Sharon van den Brink, Bas van der Veer, AnneMarie van den Brandt, Florian Zwagemaker, Dennis Schmitz, Chantal Reusken, on behalf of the national COVID-19 response team

Adam Meijer, Harry Vennema, Dirk Eggink, Jeroen Cremer, Sharon van den Brink, Bas van der Veer, AnneMarie van den Brandt, Florian Zwagemaker, Dennis Schmitz, Chantal Reusken, on behalf of the AnneMarie van den Brandt, Florian $Z$

national COVID-19 response team AnneMarie van den Brandt, Florian Zwagemaker, Dennis Schmitz, Chantal Reusken, on behalf of the national COVID-19 response team

Adam Meijer, Harry Vennema, Dirk Eggink, Jeroen Cremer, Sharon van den Brink, Bas van der Veer, AnneMarie van den Brandt, Florian Zwagemaker, Dennis Schmitz, Chantal Reusken, on behalf of the national COVID-19 response team

Adam Meijer, Harry Vennema, Dirk Eggink, Jeroen Cremer, Sharon van den Brink, Bas van der Veer, AnneMarie van den Brandt, Florian Zwagemaker, Dennis Schmitz, Chantal Reusken, on behalf of the national COVID-19 response team

Adam Meijer, Harry Vennema, Dirk Eggink, Jeroen Cremer, Sharon van den Brink, Bas van der Veer, AnneMarie van den Brandt, Florian Zwagemaker, Dennis Schmitz, Chantal Reusken, on behalf of the national COVID-19 response team

Adam Meijer, Harry Vennema, Dirk Eggink, Jeroen Cremer, Sharon van den Brink, Bas van der Veer, AnneMarie van den Brandt, Florian Zwagemaker, Dennis Schmitz, Chantal Reusken, on behalf of the national COVID-19 response team

Adam Meijer, Harry Vennema, Dirk Eggink, Jeroen Cremer, Sharon van den Brink, Bas van der Veer, AnneMarie van den Brandt, Florian Zwagemaker, Dennis Schmitz, Chantal Reusken, on behalf of the national COVID-19 response team

Adam Meijer, Harry Vennema, Dirk Eggink, Jeroen Cremer, Sharon van den Brink, Bas van der Veer, AnneMarie van den Brandt, Florian Zwagemaker, Dennis Schmitz, Chantal Reusken, on behalf of the national COVID-19 response team

Adam Meijer, Harry Vennema, Dirk Eggink, Jeroen Cremer, Sharon van den Brink, Bas van der Veer, AnneMarie van den Brandt, Florian Zwagemaker, Dennis Schmitz, Chantal Reusken, on behalf of the national COVID-19 response team

Adam Meijer, Harry Vennema, Dirk Eggink, Jeroen Cremer, Sharon van den Brink, Bas van der Veer, AnneMarie van den Brandt, Florian Zwagemaker, Dennis Schmitz, Chantal Reusken, on behalf of the national COVID-19 response team

Adam Meijer, Harry Vennema, Dirk Eggink, Jeroen Cremer, Sharon van den Brink, Bas van der Veer, AnneMarie van den Brandt, Florian Zwagemaker, Dennis Schmitz, Chantal Reusken, on behalf of the national COVID-19 response team

Adam Meijer, Harry Vennema, Dirk Eggink, Jeroen Cremer, Sharon van den Brink, Bas van der Veer, AnneMarie van den Brandt, Florian Zwagemaker, Dennis Schmitz, Chantal Reusken, on behalf of the national COVID-19 response team

Adam Meijer, Harry Vennema, Dirk Eggink, Jeroen Cremer, Sharon van den Brink, Bas van der Veer, AnneMarie van den Brandt, Florian Zwagemaker, Dennis Schmitz, Chantal Reusken, on behalf of the national COVID-19 response team

Adam Meijer, Harry Vennema, Dirk Eggink, Jeroen Cremer, Sharon van den Brink, Bas van der Veer, AnneMarie van den Brandt, Florian Zwagemaker, Dennis Schmitz, Chantal Reusken, on behalf of the national COVID-19 response team

Adam Meijer, Harry Vennema, Dirk Eggink, Jeroen Cremer, Sharon van den Brink, Bas van der Veer, AnneMarie van den Brandt, Florian Zwagemaker, Dennis Schmitz, Chantal Reusken, on behalf of the national COVID-19 response team

Adam Meijer, Harry Vennema, Dirk Eggink, Jeroen Cremer, Sharon van den Brink, Bas van der Veer, AnneMarie van den Brandt, Florian Zwagemaker, Dennis Schmitz, Chantal Reusken, on behalf of the national COVID-19 response team

Adam Meijer, Harry Vennema, Dirk Eggink, Jeroen Cremer, Sharon van den Brink, Bas van der Veer, AnneMarie van den Brandt, Florian Zwagemaker, Dennis Schmitz, Chantal Reusken, on behalf of the national COVID-19 response team

Adam Meijer, Harry Vennema, Dirk Eggink, Jeroen Cremer, Sharon van den Brink, Bas van der Veer, AnneMarie van den Brandt, Florian Zwagemaker, Dennis Schmitz, Chantal Reusken, on behalf of the national COVID-19 response team 
National Institute for Public

Health and the

Environment (RIVM)

National Institute for Public

Health and the

Environment (RIVM)

National Institute for Public

Health and the

Environment (RIVM)

National Institute for Public

Health and the

Environment (RIVM)

National Institute for Public

Health and the

Environment (RIVM)

National Institute for Public

Health and the

Environment (RIVM)

National Institute for Public

Health and the

Environment (RIVM)

National Institute for Public

Health and the

Environment (RIVM)

EPI_ISL_1962985 Dutch COVID-19 response team

EPI_ISL_3047866 Microvida

EPI_ISL_3047867 Microvida

EPI_ISL_2259188 Microvida

EPI ISL 2259136 Microvida

EPI_ISL_2259122 Microvida

EPI_ISL_1522131 Dutch COVID-19 response team

EPI_ISL_1792908 Dutch COVID-19 response team

EPI_ISL_1792918 Dutch COVID-19 response team

EPI_ISL_1090134 Dutch COVID-19 response team
Microvida

Microvida

Microvida

Microvida

Microvida

National Institute for Public

Health and the

Environment (RIVM)

National Institute for Public

Health and the

National Institute for Public

Health and the

Environment (RIVM)

National Institute for Public

Health and the

Environment (RIVM)
Adam Meijer, Harry Vennema, Dirk Eggink, Jeroen Cremer, Sharon van den Brink, Bas van der Veer, AnneMarie van den Brandt, Florian Zwagemaker, Dennis Schmitz, Chantal Reusken, on behalf of the national COVID-19 response team

Adam Meijer, Harry Vennema, Dirk Eggink, Jeroen Cremer, Sharon van den Brink, Bas van der Veer, AnneMarie van den Brandt, Florian Zwagemaker, Dennis Schmitz, Chantal Reusken, on behalf of the national COVID-19 response team

Adam Meijer, Harry Vennema, Dirk Eggink, Jeroen Cremer, Sharon van den Brink, Bas van der Veer, AnneMarie van den Brandt, Florian Zwagemaker, Dennis Schmitz, Chantal Reusken, on behalf of the national COVID-19 response team

Adam Meijer, Harry Vennema, Dirk Eggink, Jeroen Cremer, Sharon van den Brink, Bas van der Veer, AnneMarie van den Brandt, Florian Zwagemaker, Dennis Schmitz, Chantal Reusken, on behalf of the national COVID-19 response team

Adam Meijer, Harry Vennema, Dirk Eggink, Jeroen Cremer, Sharon van den Brink, Bas van der Veer, AnneMarie van den Brandt, Florian Zwagemaker, Dennis Schmitz, Chantal Reusken, on behalf of the national COVID-19 response team

Adam Meijer, Harry Vennema, Dirk Eggink, Jeroen Cremer, Sharon van den Brink, Bas van der Veer, AnneMarie van den Brandt, Florian Zwagemaker, Dennis Schmitz, Chantal Reusken, on behalf of the national COVID-19 response team

Adam Meijer, Harry Vennema, Dirk Eggink, Jeroen Cremer, Sharon van den Brink, Bas van der Veer, AnneMarie van den Brandt, Florian Zwagemaker, Dennis Schmitz, Chantal Reusken, on behalf of the national COVID-19 response team

Adam Meijer, Harry Vennema, Dirk Eggink, Jeroen Cremer, Sharon van den Brink, Bas van der Veer, AnneMarie van den Brandt, Florian Zwagemaker, Dennis Schmitz, Chantal Reusken, on behalf of the national COVID-19 response team

S.D. Pas, J.J. Verweij, J. Stohr

S.D. Pas, J.J. Verweij, J. Stohr

S.D. Pas, J.J. Verweij, J. Stohr

S.D. Pas, J.J. Verweii, J. Stohr

S.D. Pas, J.J. Verweij, J. Stohr

Adam Meijer, Harry Vennema, Dirk Eggink, Jeroen Cremer, Sharon van den Brink, Bas van der Veer, AnneMarie van den Brandt, Florian Zwagemaker, Dennis Schmitz, Chantal Reusken, on behalf of the national COVID-19 response team

Adam Meijer, Harry Vennema, Dirk Eggink, Jeroen Cremer, Sharon van den Brink, Bas van der Veer, AnneMarie van den Brandt, Florian Zwagemaker, Dennis Schmitz, Chantal Reusken, on behalf of the national COVID-19 response team

Adam Meijer, Harry Vennema, Dirk Eggink, Jeroen Cremer, Sharon van den Brink, Bas van der Veer, AnneMarie van den Brandt, Florian Zwagemaker, Dennis Schmitz, Chantal Reusken, on behalf of the national COVID-19 response team

Adam Meijer, Harry Vennema, Dirk Eggink, Jeroen Cremer, Sharon van den Brink, Bas van der Veer, AnneMarie van den Brandt, Florian Zwagemaker, Dennis Schmitz, Chantal Reusken, on behalf of the AnneMarie van den Brandt, Florian
national COVID-19 response team 